Research Article

\title{
Optimisation of Longitudinal Seismic Energy Dissipation System for Straddle-type Monorail-Cum-Road Long-Span Cable-Stayed Bridge
}

\author{
Xiong Liang $\left(\mathbb{D},{ }^{1,2}\right.$ Baomu Li, ${ }^{1}$ Xiaolu Liu, ${ }^{1}$ and Linong Liang ${ }^{2}$ \\ ${ }^{1}$ School of Civil Engineering and Transportation, South China University of Technology, Guangzhou 510641, China \\ ${ }^{2}$ Guangdong Provincial Communications Planning and Design Institute Co., Ltd., Guangzhou 510507, China
}

Correspondence should be addressed to Xiong Liang; 1.x42@mail.scut.edu.cn

Received 7 March 2019; Revised 9 July 2019; Accepted 31 July 2019; Published 16 November 2019

Academic Editor: Mario Terzo

Copyright (c) 2019 Xiong Liang et al. This is an open access article distributed under the Creative Commons Attribution License, which permits unrestricted use, distribution, and reproduction in any medium, provided the original work is properly cited.

\begin{abstract}
To investigate the optimal longitudinal seismic energy dissipation system of straddle-type monorail-cum-road long-span cablestayed bridges, the Niutianyang Bridge was selected as the engineering background, and the explicit time-domain dimensionreduced iteration method was adopted to carry out nonlinear time-history analysis. To consider the dynamic characteristics of longitudinal movable supports, the static and dynamic responses of four kinds of energy dissipation systems were studied, including longitudinal unconstrained, elastic cable, viscous damper, and speed lock-up devices. The damping effect of four types of schemes in which viscous dampers were installed at piers or towers was analysed, and the parameters of the viscous dampers were optimised. The influences of the straddle-type monorail train braking force and the running vibration of the straddle-type monorail traffic on the parameters of the viscous dampers were analysed. This study shows that the viscous damper system had the lowest bending moment at the bottom of the tower and a smaller displacement response, and the energy dissipation was the best. Each viscous damper had the highest energy dissipation efficiency when they are installed only at the main tower. The damping effect was better when the damping coefficient $c$ ranged from 3500 to $5000 \mathrm{kN} \cdot(\mathrm{m} / \mathrm{s})^{-\alpha}$ and the velocity exponent $\alpha$ ranged from 0.35 to 0.5 . The static friction of the straddle-type monorail-cum-road long-span cable-stayed bridge support can resist the trains' braking force, and the parameters of the viscous damper can be selected regardless of train braking. A suitably large value of velocity exponent $\alpha$ may be required to increase the working velocity of the viscous damper to reduce the damper's participation in the process of the train crossing the bridge.
\end{abstract}

\section{Introduction}

Straddle-type monorail-cum-road bridges fulfil the functions of highway and monorail traffic on a single bridge, which can save bridge resources, reduce engineering investment, reduce the impact of bridges on the water environment [1], and afford greater environmental protection. In addition to these advantages, the structural features of straddle-type monorail-cum-road long-span cable-stayed bridges such as tower height, pile length, and weak damping make their seismic response relatively unfavourable [2], and these special bridges are generally located at key positions of the route. Their destruction in the earthquake can lead to traffic disruption, hinder rescue work, and cause huge losses of economic and life. Compared with highway cable-stayed bridges, straddle-type monorail-cum-road cable-stayed bridges also shoulder the special responsibility of ensuring the safety of trains, so a mean to ensure the safety of the structure under the action of large earthquakes and to ensure the safety of trains is a problem that engineers have always found difficult [3].

Many scholars have studied energy dissipation systems and the parameter optimisation problems of highway or railway cable-stayed bridges. The control objective of cablestayed bridges with a partially longitudinal constraint system is to yield maximum reductions in the base forces of bridge towers that are longitudinally restricted with the bridge deck [4]. The dynamic responses of cable-stayed bridges depend 
largely on the connections between towers and beams [5-7]. During seismic excitations, the tower beam consolidation system can reduce the longitudinal displacements of the beam end and the top of the tower, but the internal forces of the tower will increase significantly. The floating system is completely unconstrained between the tower beams, and although the internal force responses of the towers are small, the main girder and the top of the tower will undergo a large longitudinal displacement. A semifloating system with the vertical support between the tower and the girder is more often used in such projects, and the structural response is reduced with the addition of suitable longitudinal restraint devices [8-11]. In addition, few studies have examined the energy dissipation systems of rail-cum-road cable-stayed bridges. The viscous damper system is an ideal structural seismic system $[2,12]$. The damper's degree of participation while a train is braking can be adjusted by designing the velocity exponent of the viscous damper $[3,13]$. A hybrid control scheme that includes a magnetorheological damper and a liquid viscous damper can also be used; when the earthquake occurs, the main beam's longitudinal vibration response is mainly suppressed by the liquid viscous damper, and when the train brakes, it is mainly suppressed by the magnetorheological damper [14]. The collapse process and failure mechanism of rail-cum-road cable-stayed bridges have been studied under strong seismic excitations [15]. The effects of uniform temperature changes on the seismic responses of a cable-stayed bridge have also been discussed [16].

Some studies have examined the interaction of monorail trains, earthquakes, and bridges. Kim et al. $[17,18]$ studied the seismic responses of a monorail bridge involving the train-bridge interaction. Lee et al. [19] analysed the trafficinduced dynamic responses of a monorail steel bridge and train. Wang et al. [20] analysed the dynamic responses of a monorail bridge-vehicle coupling system on the effects of speed and three kinds of loads and various radii of curvature on the dynamic responses of the monorail bridge-vehicle coupling system. However, these studies focused mainly on single-track beam bridges, not on large-span complex bridges with track beams installed.

Unlike ordinary railways, the maximum running speed of a straddle-type monorail train is generally less than $80 \mathrm{~km} / \mathrm{h}$. So, the speed is low, and the train grouping is generally no more than six vehicles. Therefore, the total mass is low, and the train's dynamic response differs greatly from that of ordinary trains $[21,22]$. Thus, the research results for the energy dissipation system with monorail bridges and ordinary railway cable-stayed bridges are not fully adapted to straddle-type monorail-cum-road long-span cable-stayed bridges, which require further study.

To examine the longitudinal seismic energy dissipation system of straddle-type monorail-cum-road long-span cable-stayed bridges, in this study, Niutianyang Bridge is used as the actual engineering background and ANSYS software is used to establish a finite element model. And, an explicit time-domain dimension-reduced iteration method is adopted to study the difficult key issues of longitudinal seismic energy dissipation systems, such as the optimal selection of longitudinal seismic energy dissipation systems, the setting of the viscous damper position, the optimisation of the viscous damper parameters, and the effect of straddletype monorail traffic braking and running vibration on the selection of viscous damper parameters.

\section{Niutianyang Bridge}

Niutianyang Bridge, which is the key part of the Niutianyang Expressway project in Shantou city (Figure 1), is a long-span double-tower three-span cable-stayed bridge currently under construction over the Rongjiang River in South China. The bridge span is $77.5+166.1+468+166.1+77.5=$ $955.2 \mathrm{~m}$. The auxiliary pier is designed to increase the main span's stiffness. The main towers are diamond-shaped concrete bridge towers. A single tower is arranged with $4 \times 15$ cables, and the bridge adopts a semifloating system.

Figure 2 shows a standard cross section of a steel truss girder. The bridge adopts a plan of co-construction of a straddle-type monorail-cum-road: the upper deck handles six lanes of two-way automobile traffic and the lower deck is a two-line straddle-type monorail. The width and height of the steel truss girder are $37.4 \mathrm{~m}$ and $12.4 \mathrm{~m}$, respectively. The straddle-type monorail track beam adopts a continuous structure of a steel rail beam, and the standard section length is $15.1 \mathrm{~m}$, which is arranged above the lower chord beam of the main bridge steel truss girder.

Each main tower has three cross beams and rises to a height of $182.9 \mathrm{~m}$, as shown in Figure 3. The main tower foundation adopts bored piles, and 40 variable-section piles of $\varphi 3.0 \mathrm{~m}$ to $\varphi 2.5 \mathrm{~m}$ are arranged under each pile cap, designed as end-bearing piles. The plane of the main tower cap is a round-end dumbbell type, and the plane profile of the entire cap is $75 \mathrm{~m}$ (transverse) $\times 33 \mathrm{~m}$ (longitudinal).

\section{Analysis Theory, Finite Element Model, and Seismic Excitations}

3.1. Analysis Theory. To improve the efficiency of computational analysis and reduce the calculation time, seismic response analysis has been carried out with the explicit timedomain dimension-reduced iteration method proposed by $\mathrm{Su}$ and his coauthors; the main theory can be found in references [23-25].

The equivalent excitation vector $\mathbf{F}_{j}$ at time instant $t_{j}$ is associated with the ground motion acceleration $X_{j}$ and the velocity vector $\dot{\mathbf{U}}_{D, j}$ of the nodes of damping at the same time instant. The explicit expression of the structural response at each time instant can be rewritten as

$$
\begin{aligned}
\mathbf{V}_{i}= & \mathbf{A}_{i, 0} \mathbf{F}_{0}\left(X_{0}, \dot{\mathbf{U}}_{D, 0}\right)+\mathbf{A}_{i, 1} \mathbf{F}_{1}\left(X_{1}, \dot{\mathbf{U}}_{D, 1}\right)+\cdots+\mathbf{A}_{i, i-1} \mathbf{F}_{i-1} \\
& \cdot\left(X_{i-1}, \dot{\mathbf{U}}_{D, i-1}\right)+\mathbf{A}_{i, i} \mathbf{F}_{i}\left(X_{i}, \dot{\mathbf{U}}_{D, i}\right), \quad i=1,2, \ldots, l,
\end{aligned}
$$

where the coefficient matrices $\mathbf{A}_{i, j}(j=0,1, \ldots, i)$ can be arranged in the form as shown in Table 1 , which indicates that only the coefficient matrices $\mathbf{A}_{i, 0}$ and $\mathbf{A}_{i, 1}(i=1,2, \ldots, l)$ in the first two columns must be calculated and stored, whilst 


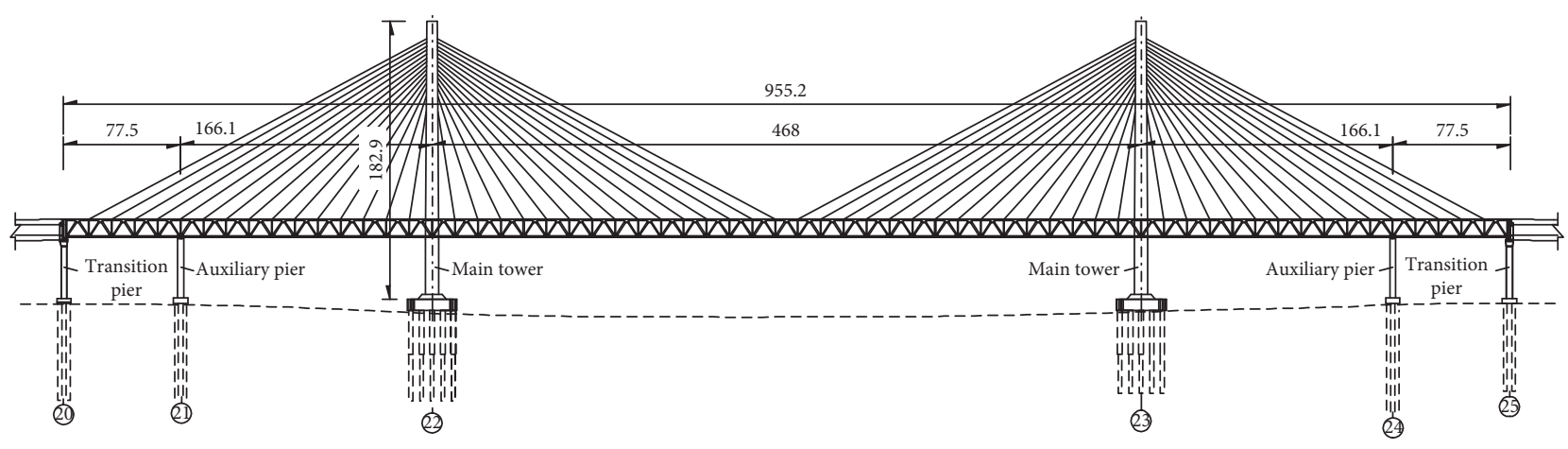

Figure 1: Elevation layout of Niutianyang Bridge (unit: m).

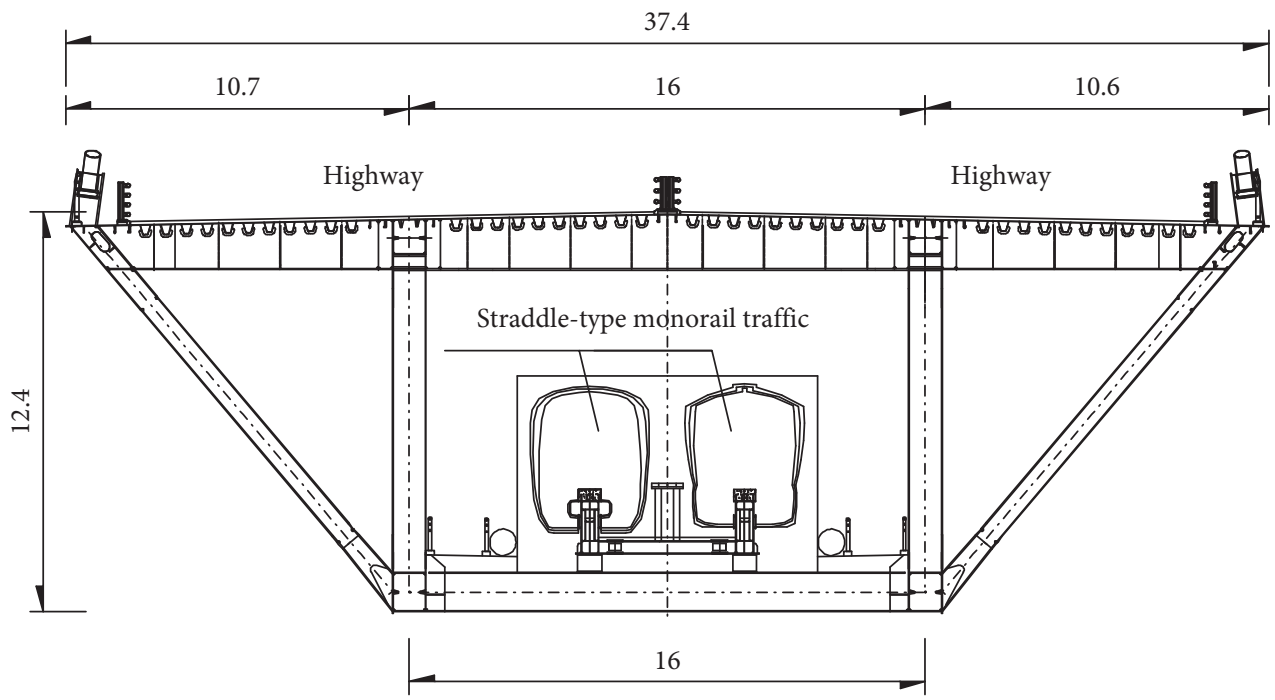

FIGURE 2: Standard cross section of steel truss girder (unit: m).

the other coefficient matrices in the remaining columns can be obtained directly from those in the second column.

To improve the efficiency of nonlinear iteration, $\mathbf{V}_{i}$ in equation (1) can be divided into two parts with the advantage of explicit representation of the state vector. The first part is $\dot{\mathbf{U}}_{D, i}$, which is the only part associated with the nonlinear portion of the damping forces, and the other part can be denoted by $\mathbf{V}_{R, i}$, which is the remainder of $\mathbf{V}_{i}$ except for $\dot{\mathbf{U}}_{D, i}$. Correspondingly, equation (1) can be divided into two parts as equations (2) and (3):

$$
\begin{aligned}
\dot{\mathbf{U}}_{D, i}= & \mathbf{A}_{i, 0}^{D} \mathbf{F}_{0}\left(X_{0}, \dot{\mathbf{U}}_{D, 0}\right)+\mathbf{A}_{i, 1}^{D} \mathbf{F}_{1}\left(X_{1}, \dot{\mathbf{U}}_{D, 1}\right)+\cdots+\mathbf{A}_{i, i-1}^{D} \mathbf{F}_{i-1} \\
& \cdot\left(X_{i-1}, \dot{\mathbf{U}}_{D, i-1}\right)+\mathbf{A}_{i, i}^{D} \mathbf{F}_{i}\left(X_{i}, \dot{\mathbf{U}}_{D, i}\right), \quad i=1,2, \ldots, l,
\end{aligned}
$$

$$
\begin{aligned}
\mathbf{V}_{R, i}= & \mathbf{A}_{i, 0}^{R} \mathbf{F}_{0}\left(X_{0}, \dot{\mathbf{U}}_{R, 0}\right)+\mathbf{A}_{i, 1}^{R} \mathbf{F}_{1}\left(X_{1}, \dot{\mathbf{U}}_{R, 1}\right)+\cdots+\mathbf{A}_{i, i-1}^{R} \mathbf{F}_{i-1} \\
& \cdot\left(X_{i-1}, \dot{\mathbf{U}}_{R, i-1}\right)+\mathbf{A}_{i, i}^{R} \mathbf{F}_{i}\left(X_{i}, \dot{\mathbf{U}}_{R, i}\right), \quad i=1,2, \ldots, l
\end{aligned}
$$

where $\mathbf{A}_{i, j}^{D}$ and $\mathbf{A}_{i, j}^{R}$ consist of the rows simply extracted from $\mathbf{A}_{i, j}$ with respect to $\dot{\mathbf{U}}_{D, i}$ and $\mathbf{V}_{R, i}$, respectively.

It can be observed from equation (2) that the nonlinear iteration can now be carried out focusing only on $\dot{\mathbf{U}}_{D, i}$. Once
$\dot{\mathbf{U}}_{D, i}$ is known, the other responses in $\mathbf{V}_{R, i}$ can be obtained directly using equation (3) with no further iteration.

Note that, for the purpose of structural design, not all structural responses are required, and only a certain number of critical responses require focus. In other words, if dimension-reduced calculation of responses can be conducted in this process, the efficiency for the analysis will be further enhanced. Obviously, the explicit formulation for $\mathbf{V}_{R, i}$ shown in equation (3) can meet this requirement. Suppose that $s_{i}$ is a critical response component of interest in $\mathbf{V}_{R, i}$. From equation (3), $s_{i}$ can then be directly obtained as

$$
\begin{aligned}
s_{i}= & \mathbf{a}_{i, 0}^{s} \mathbf{F}_{0}\left(X_{0}, \dot{\mathbf{U}}_{D, 0}\right)+\mathbf{a}_{i, 1}^{s} \mathbf{F}_{1}\left(X_{1}, \dot{\mathbf{U}}_{D, 1}\right)+\cdots+\mathbf{a}_{i, i-1}^{s} \mathbf{F}_{i-1} \\
& \cdot\left(X_{i-1}, \dot{\mathbf{U}}_{D, i-1}\right)+\mathbf{a}_{i, i}^{s} \mathbf{F}_{i}\left(X_{i}, \dot{\mathbf{U}}_{D, i}\right), \quad i=1,2, \ldots, l,
\end{aligned}
$$

where $\mathbf{a}_{i, j}^{s}$ is the corresponding row vector of $\mathbf{A}_{i, j}^{R}(j=1,2, \ldots, i)$ with respect to $s_{i}$.

In summary, with the use of the time-domain explicit expressions of responses shown in equation (1), dimensionreduced analysis can be easily conducted in the process of time-history analysis of the damping structure equipped with damping devices, including the dimension-reduced iteration solution for the velocity components of the nodes 

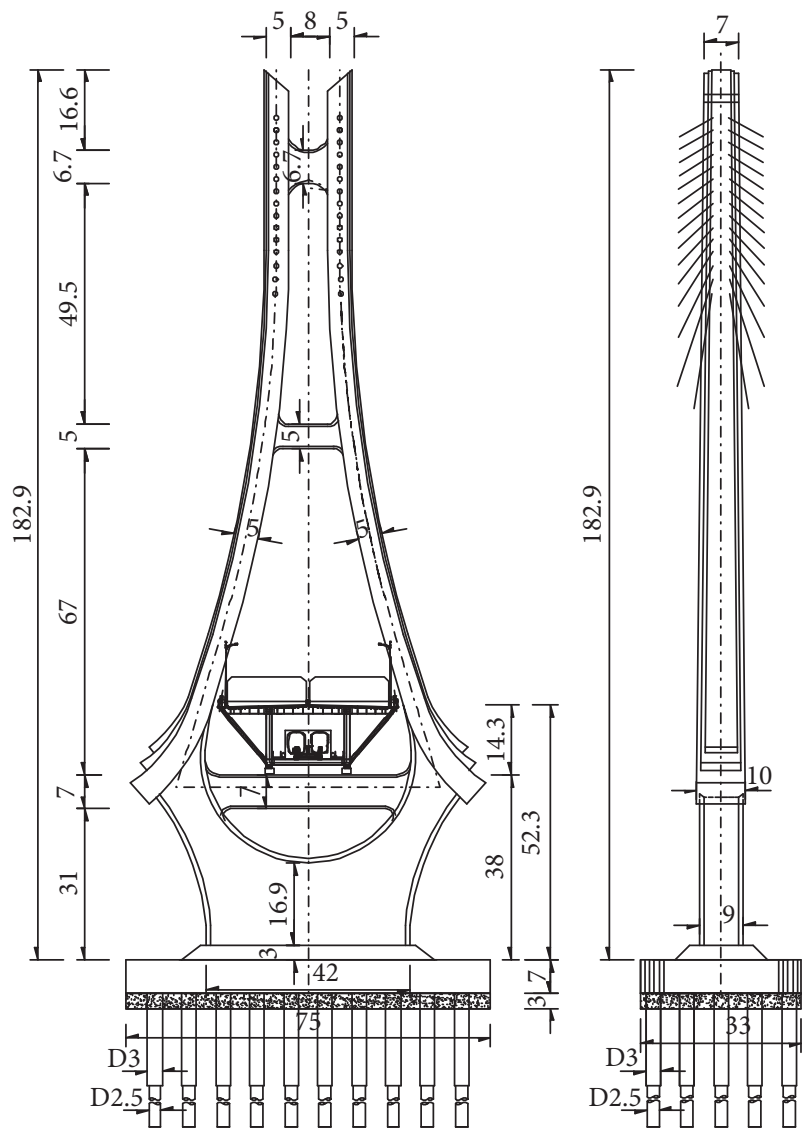

Figure 3: Elevation of main tower (unit: $\mathrm{m}$ ).

TABle 1: Coefficient matrices for each time instant.

\begin{tabular}{lcccccccc}
\hline \multirow{2}{*}{ Time instant } & \multicolumn{8}{c}{ Coefficient matrix } \\
& $\mathbf{F}_{0}$ & $\mathbf{F}_{1}$ & $\mathbf{F}_{2}$ & $\mathbf{F}_{3}$ & $\ldots$ & $\mathbf{F}_{l-2}$ & $\mathbf{F}_{l-1}$ & $\mathbf{F}_{l}$ \\
\hline$t_{1}$ & $\mathbf{A}_{1,0}$ & $\mathbf{A}_{1,1}$ & & & & & & \\
$t_{2}$ & $\mathbf{A}_{2,0}$ & $\mathbf{A}_{2,1}$ & $\mathbf{A}_{1,1}$ & & & & & \\
$t_{3}$ & $\mathbf{A}_{3,0}$ & $\mathbf{A}_{3,1}$ & $\mathbf{A}_{2,1}$ & $\mathbf{A}_{1,1}$ & & & & \\
$\square$ & $\square$ & $\square$ & $\square$ & $\square$ & $\square$ & & & \\
$t_{l-2}$ & $\mathbf{A}_{l-2,0}$ & $\mathbf{A}_{l-2,1}$ & $\mathbf{A}_{l-2,2}$ & $\mathbf{A}_{l-2,3}$ & $\ldots$ & $\mathbf{A}_{1,1}$ & & \\
$t_{l-1}$ & $\mathbf{A}_{l-1,0}$ & $\mathbf{A}_{l-1,1}$ & $\mathbf{A}_{l-1,2}$ & $\mathbf{A}_{l-1,3}$ & $\ldots$ & $\mathbf{A}_{2,1}$ & $\mathbf{A}_{1,1}$ & \\
$t_{l}$ & $\mathbf{A}_{l, 0}$ & $\mathbf{A}_{l, 1}$ & $\mathbf{A}_{l, 2}$ & $\mathbf{A}_{l, 3}$ & $\ldots$ & $\mathbf{A}_{3,1}$ & $\mathbf{A}_{2,1}$ & $\mathbf{A}_{1,1}$ \\
\hline
\end{tabular}

of the damping devices using equation (2) and then the dimension-reduced calculation for the other critical responses concerned using equation (4). The above procedure is particularly suitable for time-history analysis of structures with local nonlinearities, and the computational cost is significantly lower than that of the traditional nonlinear time-history analysis methods.

The method uses the established structural finite element model to perform time-history analysis under the action of half-triangle and full-triangle unit pulse ground motion acceleration, obtains the coefficient vector of the seismic excitations' effect at each time point, and establishes the explicit expression of the structural dynamic response. A self-made MATLAB program is then used to complete the structural calculation and statistical analysis of the results based on the explicit expression of the dynamic response.
3.2. Finite Element Model. A finite element model of Niutianyang Bridge was established using the general-purpose finite element software ANSYS, and five spans of the approach bridge models were also established on each side to consider their influences on the dynamic characteristics of the main bridge. The finite element model of Niutianyang Bridge is shown in Figure 4. The $x$-axis lies in the longitudinal direction, the $y$-axis lies in the transverse bridge direction, and the $z$-axis lies in the vertical bridge direction. Three-dimensional beam elements are used to model the main girder trusses and the main towers. The shell elements are used to simulate the highway steel bridge deck and the lower main tower which is a single-box three-room section, and the link elements are used to simulate the stay cables. The entire model consists of 7,378 elements.

According to the Chinese highway bridge design specification "Specifications for Design of Highway Reinforced Concrete and Prestressed Concrete Bridges and Culverts" (JTG 3362-2018), the material parameters in the finite element model are as follows: the main beam steel of the main bridge: the elastic modulus is $2.00 \times 10^{5} \mathrm{MPa}$, Poisson's ratio is 0.3 , the density is $7,850 \mathrm{~kg} / \mathrm{m}^{3}$, and the thermal expansion coefficient is 0.000012; the cable steel: the elastic modulus is $2.05 \times 10^{5} \mathrm{MPa}$, Poisson's ratio is 0.3 , the density of the cable steel is $7,850 \mathrm{~kg} / \mathrm{m}^{3}$, and the thermal expansion coefficient is 0.000012; the reinforced concrete of the main tower, pier, and main beam of the approach bridge: elastic modulus is $3.45 \times 10^{4} \mathrm{MPa}$, Poisson's ratio is 0.2 , density is $2600 \mathrm{~kg} / \mathrm{m}^{3}$, and thermal expansion coefficient is 0.000010 .

The effects of the pile foundation were simulated by adding spring stiffness in six directions at the bottom of the cap of the main tower. The spring stiffness was determined by the static equivalent principle according to the condition of the soil layer and the arrangement of the piles. The effects of the second-stage dead load on the structure's dynamic characteristics were considered, the second-stage dead load is $2.86 \mathrm{kN} / \mathrm{m}^{2}$ and is applied to the steel bridge deck, and the load is converted into structural quality when the dynamic characteristics are calculated. The bridge's completion state was obtained via the analysis in which geometric nonlinear effects, including the large displacement, stress-stiffening effects under the dead load of the bridge, and the $P$ - $\triangle$ effect of the tower and pier, were taken into consideration.

The nonlinear behavior of cables which simulated by link elements is considered from Chinese highway bridge design specification "Guidelines for Design of Highway CableStayed Bridges" (JTG/T D65-01-2007, Section 6.2.4), the elastic modulus of the stay cable is modified by the Ernst formula. The formula is shown as equation (5). In the finite element model, the nonlinear analysis of the stay cable is realized through changing the elastic modulus of the stay cable by updating the cable tension stress:

$$
E=\frac{E_{0}}{1+\left(\left((\gamma S \cos \alpha)^{2}\right) /\left(12 \sigma^{3}\right)\right) E_{0}},
$$

where $E$ is the converted elastic modulus of the stay cable considering the influence of the slack of cable, $E_{0}$ is the elastic modulus of the steel of the stay cable, $\gamma$ is the cable 


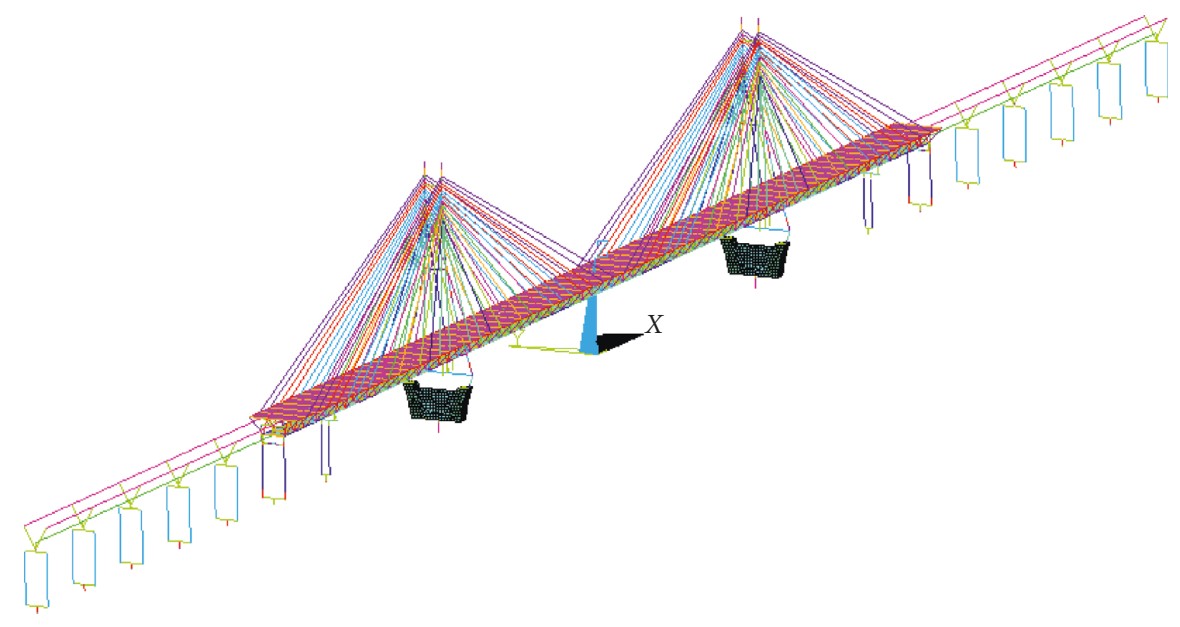

FIGURE 4: Finite element model of Niutianyang Bridge by software ANSYS.

weight per unit volume, $S$ is the length of the stay cable, $\alpha$ is the angle between the stay cable and the horizontal line, and $\sigma$ is the cable tension stress.

The MIDAS CIVIL-FEM was also established for the calculation of the ultimate limit state of the load capacity of the main bridge, as shown in Figure 5. The dynamic characteristics of the completion state of the Niutianyang Bridge by ANSYS-FEM and MIDAS CIVIL-FEM are both listed in Table 2 . The main dynamic characteristics obtained by the two different software FEM are very close, indicating the correctness of the finite element models. The first fourorder modes of the Niutianyang Bridge are shown in Figure 6.

3.3. Seismic Excitation. According to the "Seismic Safety Evaluation Report of Niutianyang Expressway Engineering Site," in the seismic response analysis, the ground acceleration response spectrum with the exceedance probability of $4 \%$ in 100 years was taken as the horizontal seismic excitation. The vertical seismic excitation is two-thirds of the horizontal seismic excitation. The horizontal design acceleration response spectrum is shown in the following equation:

$$
S_{a}(T)= \begin{cases}S_{A \max }(0.4+6.0 T), & 0 \mathrm{~s} \leq T<0.1 \mathrm{~s}, \\ S_{A \max }, & 0.1 \mathrm{~s} \leq T<T_{g}, \\ S_{A \max }\left(\frac{T_{g}}{T}\right)^{\gamma}, & T_{g} \leq T<10 \mathrm{~s},\end{cases}
$$

where $S_{A \text { max }}$ is the maximum value of the horizontal design acceleration response spectrum of the site, $T_{g}$ is the characteristic period, and $\gamma$ is the index; and the values of this bridge are $1.05 \mathrm{~g}, 0.85 \mathrm{~s}$, and 1.0 , respectively.

The ground motion acceleration time history of the site design is synthesized by fitting the site design acceleration response spectrum and the intensity envelope function. During the calculation of the ground motion acceleration time history, the number of fitting control points of the target response spectrum is 67 , the minimum period of the control point is $0.04 \mathrm{~s}$, and the maximum period is $10.0 \mathrm{~s}$. The relative error of the iterative control of the fitted spectrum and the target spectrum is controlled within $5 \%$. Seven ground motion acceleration time-history samples with a duration of $T_{d}=65 \mathrm{~s}$ are shown in Figure 7, where the time interval is $0.02 \mathrm{~s}$ and the unit of ground motion acceleration time history is $\mathrm{m} / \mathrm{s}^{2}$.

The explicit time-domain dimension-reduced iteration method described in Section 3.1 is used to analyse the structural responses of the seven seismic waves. The average of the seven seismic wave responses is taken as the final output.

3.4. Computational Accuracy and Efficiency. Nonlinear timehistory analysis of the Niutianyang Bridge was conducted using the explicit time-domain dimension-reduced iteration method presented in Section 3.1. The structural matrices $\mathbf{M}$, $\mathbf{C}$, and $\mathbf{K}$ required in our method were extracted from the baseline model of the bridge established on the ANSYS software platform. To demonstrate the accuracy and efficiency of the present approach, nonlinear time-history analysis is also carried out using the finite element software ANSYS. In the above two methods, the sample of longitudinal seismic excitation, as shown in Figure 7(a), is taken to be the input of ground motion.

The longitudinal displacement at midspan of the main girder is shown in Figure 8 and the longitudinal bending moment at the bottom section of the main tower is shown in Figure 9, respectively. It can be seen from Figures 8 and 9 that the results of the present method are in good agreement with those obtained with ANSYS, indicating the validity of the explicit time-domain dimension-reduced iteration method.

For computational efficiency, the time required by the present method is $47.0 \mathrm{~s}$, whilst a total time of $2638.0 \mathrm{~s}$ is needed when ANSYS is used for the nonlinear time-history analysis. In fact, the elapsed time of our method includes two 


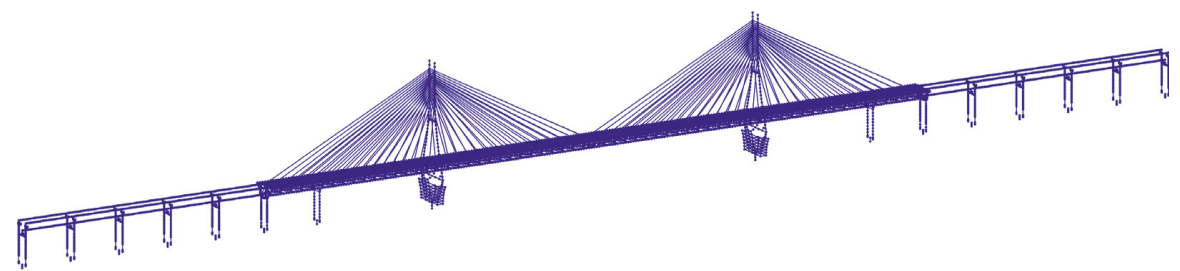

FIGURe 5: Finite element model of Niutianyang Bridge by software MIDAS CIVIL.

TABle 2: Niutianyang Bridge dynamic characteristics.

\begin{tabular}{lccc}
\hline Mode & ANSYS-FEM frequency $(\mathrm{Hz})$ & MIDAS CIVIL-FEM frequency $(\mathrm{Hz})$ & Mode shape description \\
\hline 1 & 0.101 & 0.101 & Main beam longitudinal drift \\
2 & 0.216 & 0.215 & Main beam lateral bending \\
3 & 0.329 & 0.328 & Main beam lateral bending \\
4 & 0.337 & 0.336 & Main beam vertical bending \\
5 & 0.350 & 0.349 & Main tower longitudinal bending \\
6 & 0.572 & 0.570 & Main beam vertical bending \\
7 & 0.612 & 0.610 & Main tower lateral bending \\
8 & 0.629 & 0.627 & Main tower lateral bending \\
\hline
\end{tabular}

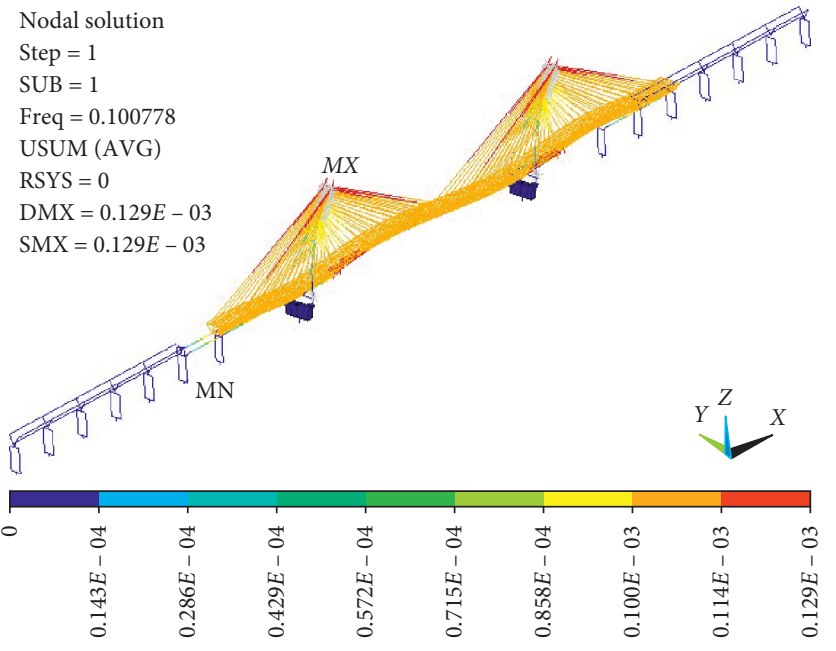

Nodal solution

Step $=1$

$\mathrm{SUB}=3$

Freq $=0.328943$

USUM (AVG)

RSYS $=0$

$\mathrm{DMX}=0.296 E-03$

$\mathrm{SMX}=0.296 E-03$

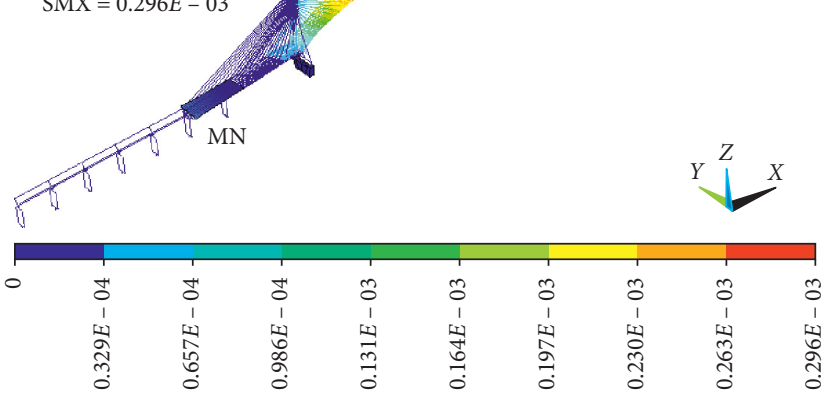

Nodal solution

Step $=1$

SUB $=2$

Freq $=0.216206$

USUM (AVG)

RSYS $=0$

$\mathrm{DMX}=0.247 E-03$

SMX $=0.247 E-03$
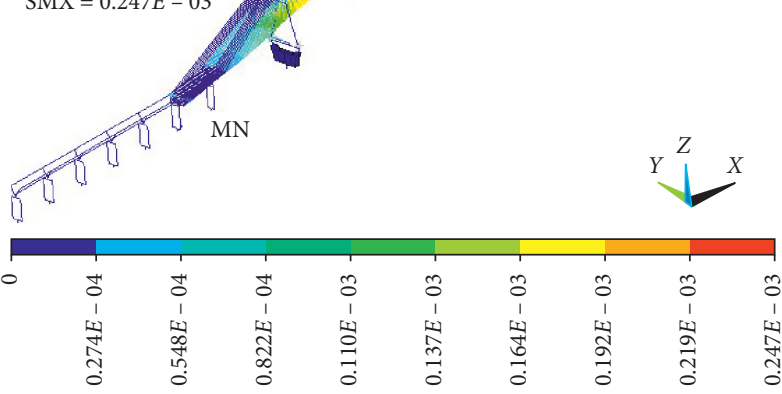

Nodal solution

Step $=1$

$\mathrm{SUB}=4$

Freq $=0.337252$

USUM (AVG)

RSYS $=0$

$\mathrm{DMX}=0.305 E-03$

$\mathrm{SMX}=0.305 E-03$

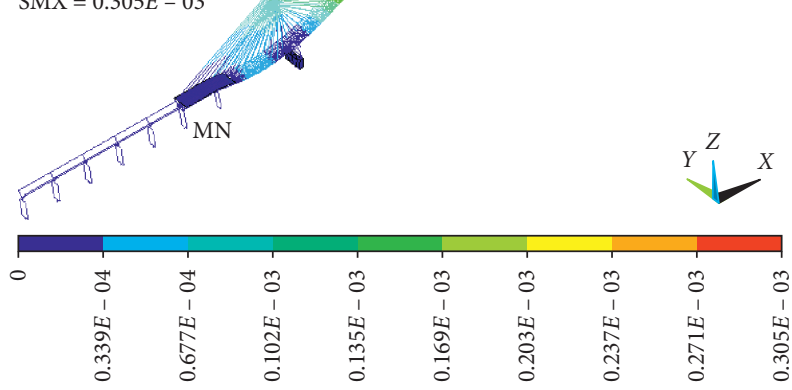

Figure 6: Mode shapes of Niutianyang Bridge. (a) Mode 1. (b) Mode 2. (c) Mode 3. (d) Mode 4. 


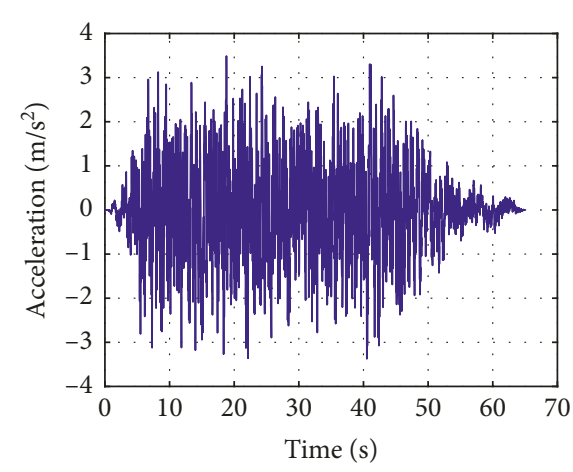

(a)

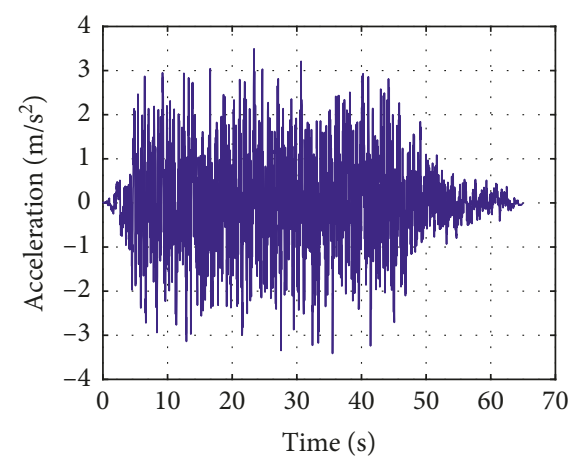

(c)

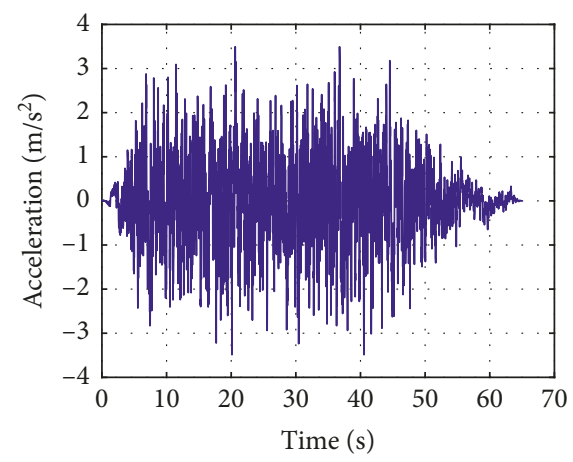

(e)

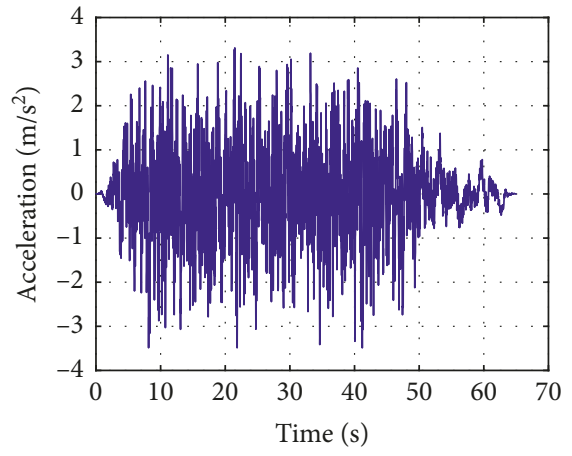

(b)

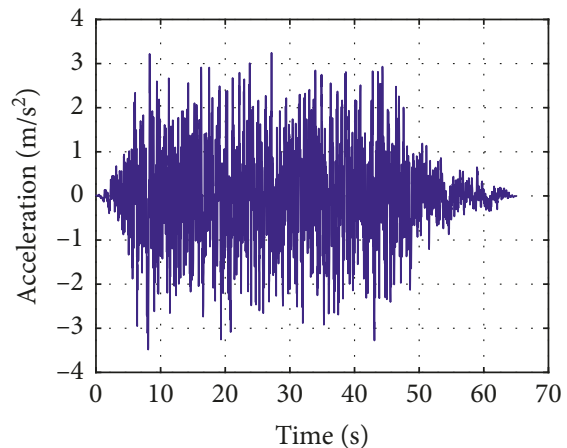

(d)

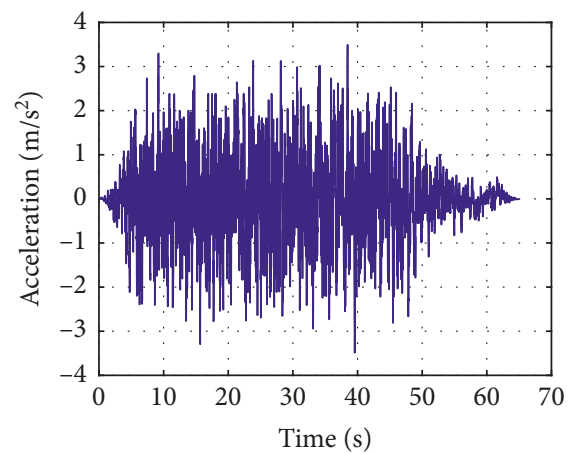

(f)

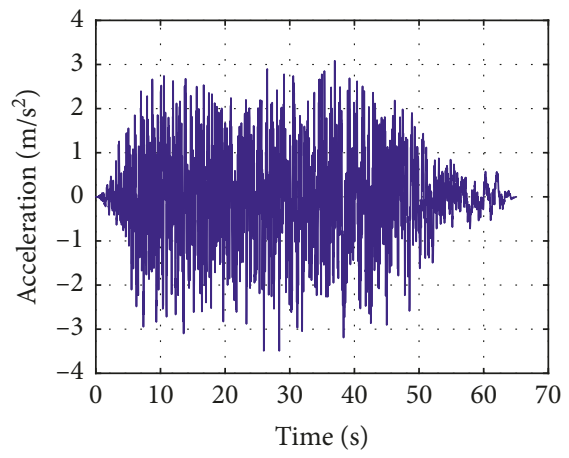

(g)

FIGURE 7: Samples of acceleration time history.

parts. The first part, $44.3 \mathrm{~s}$, is used to calculate the coefficient matrices in the explicit expressions of the dynamic responses, and the second part, $2.7 \mathrm{~s}$, is spent on the dimension-reduced calculation. Apparently, our method has a much lower computational cost than the traditional nonlinear time-history analysis method. 


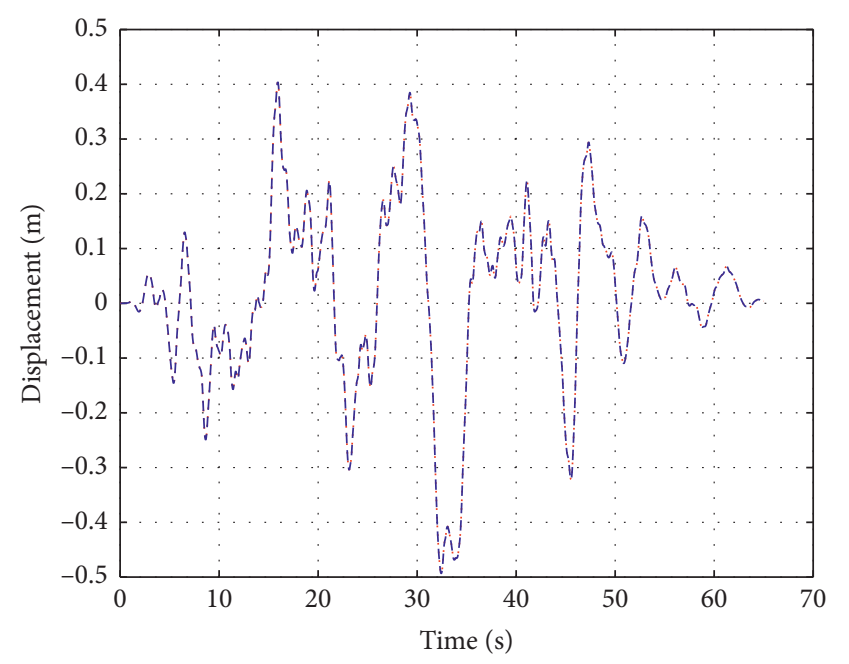

..... Nonlinear time-history analysis with ANSYS

- - - Explicit time-domain dimension-reduced iteration method

FIgURE 8: Longitudinal displacement at midspan of the main girder.

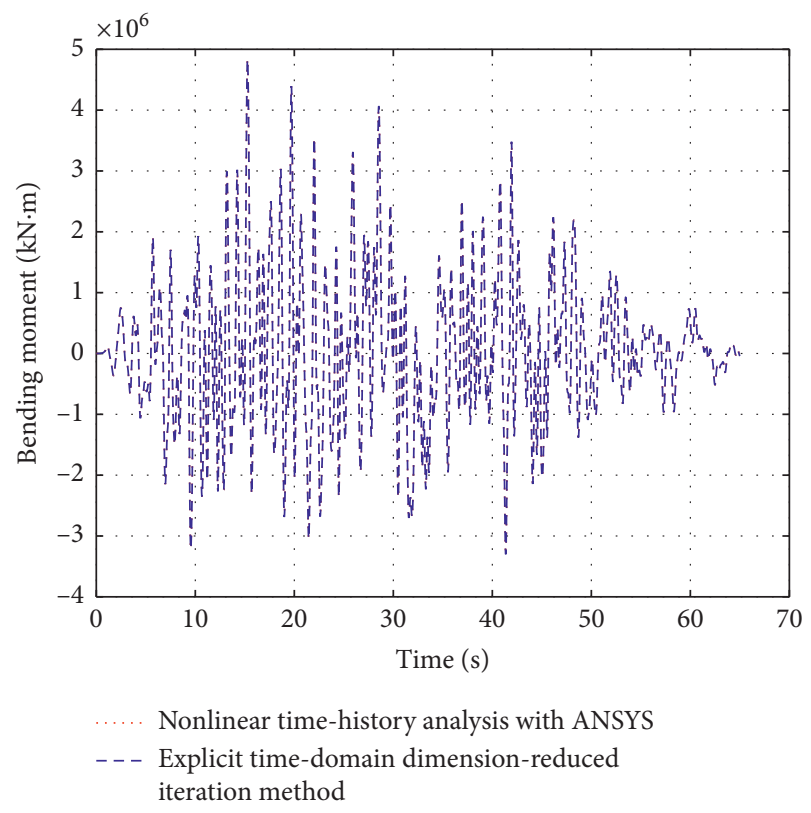

FIGURE 9: Longitudinal bending moment at the bottom section of the main tower.

\section{Optimal Selection of Longitudinal Seismic Energy Dissipation Systems}

4.1. Effects of Dynamic Characteristics of Movable Supports on Seismic Response. To investigate the contribution of the dynamic characteristics of the longitudinal spherical movable steel supports to bridge energy dissipation for the semifloating system cable-stayed bridge, three case considerations of the supports' dynamic characteristics were studied in the structural seismic response analysis. For case 1, the full bridge does not consider the dynamic characteristics of the support and the longitudinal direction is not constrained. Case 2 considers the dynamic characteristics of the support at the main tower and auxiliary pier. For case 3, the full bridge considers the dynamic characteristics of the support. When the structural dynamic analysis does not involve the dynamic stiffness of the movable support, its stiffness and yield strength were considered to be zero. The movable steel support was simulated by the approximate ideal elastoplastic element. Figure 10 shows the friction slip hysteresis model. Table 3 shows the dynamic parameters of the single movable support. And, Table 4 compares the structural seismic longitudinal response results.

Table 4 shows that, in case 1, the full-bridge movable supports do not consider the dynamic characteristics, in case 2 , the main tower and auxiliary pier movable supports consider the dynamic stiffness, and in case 3, the full-bridge movable supports consider the dynamic stiffness; the longitudinal displacement of the critical sections decreases by $11.6 \% \sim 17.1 \%$ and $15.3 \% \sim 22.4 \%$, respectively, the bending moment at the bottom section of the main tower is reduced by $5.3 \%$ and $7.0 \%$, respectively, and the bending moment of the auxiliary pier cap bottom is reduced by $32.7 \%$ and $32.9 \%$, respectively. Considering the dynamic characteristics of the movable supports, the internal force and key node displacement were greatly reduced. Therefore, for the structural seismic dynamic response analysis, the dynamic characteristics of the longitudinal spherical movable steel supports should be considered to accurately reflect the structure's structural dynamic characteristics and seismic dynamic response. The analysis results of this paper consider the dynamic characteristics of the full-bridge movable support.

\subsection{Comparison and Selection of Longitudinal Seismic Energy} Dissipation Systems. To optimise and select the longitudinal seismic energy dissipation system, four kinds of cable-stayed bridge energy dissipation systems were studied for the connection between the main tower and the main girder: a longitudinal unconstrained system, an elastic cable system, a viscous damper system, and a speed lock-up device system. The purpose of the comparative analysis was to determine the influence of the four kinds of energy dissipation systems on the structural static and dynamic responses.

The unconstrained system adopts longitudinal movable supports and considers their dynamic characteristics, and other systems are superimposed on the basis of this system. Dynamic parameters of the single longitudinal movable support are shown in Table 3. The elastic cable system is provided with four strands of $100 \phi 7$ parallel wires under each main tower, each elastic cable is $23.7 \mathrm{~m}$ long, and the elastic modulus is $2.05 \times 10^{5} \mathrm{MPa}$. The viscous damper system is provided with four viscous dampers under each main tower. The nonlinear damping force-velocity relation for fluid viscous dampers can be analytically expressed as a fractional velocity power law:

$$
f(t)=\operatorname{sign}(v) c|v|^{\alpha},
$$

where $f(t)$ denotes the damping force of the viscous damper; sign $(\cdot)$ denotes the sign function; $v$ denotes the nodal relative velocity between damper ends; and $c$ and $\alpha$ 


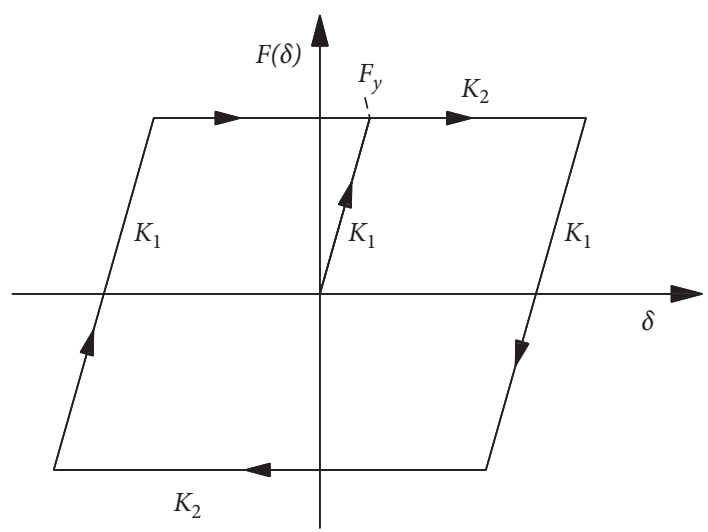

FIGURE 10: Friction slip hysteresis model of the movable support.

TABle 3: Dynamic parameters of the movable support.

\begin{tabular}{lcccc}
\hline Position & Number of supports per pier & Preyield stiffness $K_{1}(\mathrm{kN} / \mathrm{m})$ & Postyield stiffness $K_{2}(\mathrm{kN} / \mathrm{m})$ & Yield strength $F_{y}(\mathrm{kN})$ \\
\hline Transition pier & 2 & 123750 & 1.2 & 247.5 \\
Auxiliary pier & 2 & 160500 & 1.6 & 321 \\
Main tower & 2 & 60000 & 0.6 & 120 \\
\hline
\end{tabular}

TABLE 4: Structural seismic longitudinal response results of the three considerations.

\begin{tabular}{lcc}
\hline Seismic response & Case 1 & Case 2 \\
\hline $\begin{array}{l}\text { Relative displacement of the main tower and main } \\
\text { girder }(\mathrm{m})\end{array}$ & 1.151 & 0.994 \\
$\begin{array}{l}\text { Displacement at the top section of the main tower }(\mathrm{m}) \\
\begin{array}{l}\text { Displacement at the end section of the main } \\
\text { girder }(\mathrm{m})\end{array}\end{array}$ & 1.403 & 1.241 \\
$\begin{array}{l}\text { Relative displacement of the main girder between the } \\
\text { main bridge and the approach bridge }(\mathrm{m})\end{array}$ & 1.244 & 1.084 \\
$\begin{array}{l}\text { Bending moment at the bottom section of the main } \\
\text { tower }(\mathrm{MN} \cdot \mathrm{m})\end{array}$ & 0.936 & 0.776 \\
$\begin{array}{l}\text { Bending moment at the bottom section of the } \\
\text { auxiliary pier }(\mathrm{MN} \cdot \mathrm{m})\end{array}$ & 6380.2 & 6044.7 \\
\hline
\end{tabular}

denote the damping coefficient and the velocity exponent of the viscous damper, respectively. Each damper's damping coefficient is $c=3500 \mathrm{kN} \cdot(\mathrm{m} / \mathrm{s})^{-\alpha}$, and its velocity exponent $\alpha=0.4$.

The speed lock-up device system is installed with four sets under each main tower; the locking force model is expressed by equation (7), and each speed lock-up device's damping coefficient is $c=4000 \mathrm{kN} \cdot(\mathrm{m} / \mathrm{s})^{-\alpha}$, and its velocity exponent is $\alpha=2$.

Table 5 shows the structural response comparisons of the four longitudinal seismic energy dissipation systems under static action and seismic conditions.

Several observations can be made from Table 5. Static action, the viscous damper system, and the speed lock-up device system exert no constraint on the slow load of the vehicle load and temperature, so the structural response under static action is the same as that of the unconstrained system. The elastic cable system strengthens the connection between the main tower and the main girder, and under the vehicle's load, the bending moment at the bottom section of the main tower is reduced by $21.3 \%$ from the unconstrained system. However, under the action of temperature, the bending moment at the bottom section of the main tower is 85.2\% higher than that of the unconstrained system.

With seismic excitations, the displacements at the end section of the main girder of the four restraint systems are sequentially reduced. Compared with the unconstrained system, the displacements at the end section of the main girder of the elastic cable system, the viscous damper system, and the speed lock-up device system are reduced by $38.6 \%$, $54.2 \%$, and $80.5 \%$, respectively. The displacements at the end section of the main girder of the unconstrained system reach $1.033 \mathrm{~m}$ under seismic excitations, coupled with the expansion and contraction caused by temperature and other actions, which will cause great difficulties in the design of the beam expansion joint device. Compared with the viscous damper system, the relative displacement of the main girder between the main bridge and the approach bridge of the unconstrained system, the elastic cable system, and the speed lock-up device system increased by $315.0 \%, 50.3 \%$, and $2.6 \%$, respectively, whilst the bending moment at the bottom section of the main tower increased by $38.6 \%, 69.2 \%$, and 
TABLE 5: Structural response of the four longitudinal seismic energy dissipation systems.

\begin{tabular}{|c|c|c|c|c|c|}
\hline \multicolumn{2}{|c|}{ Longitudinal seismic energy dissipation system } & $\begin{array}{c}\text { Longitudinal } \\
\text { unconstrained system }\end{array}$ & $\begin{array}{l}\text { Elastic cable } \\
\text { system }\end{array}$ & $\begin{array}{l}\text { Viscous damper } \\
\text { system }\end{array}$ & $\begin{array}{l}\text { Speed lock-up } \\
\text { device system }\end{array}$ \\
\hline \multirow{2}{*}{ Car + train } & $\begin{array}{l}\text { Displacement at the end section of the } \\
\text { main girder }(\mathrm{m})\end{array}$ & 0.109 & 0.018 & 0.109 & 0.109 \\
\hline & $\begin{array}{l}\text { Bending moment at the bottom section } \\
\text { of the main tower }(\mathrm{MN} \cdot \mathrm{m})\end{array}$ & 419.4 & 329.9 & 419.4 & 419.4 \\
\hline \multirow{2}{*}{$\begin{array}{l}\text { Temperature } \\
\text { action }\end{array}$} & $\begin{array}{l}\text { Displacement at the end section of the } \\
\text { main girder }(\mathrm{m})\end{array}$ & 0.243 & 0.240 & 0.243 & 0.243 \\
\hline & $\begin{array}{l}\text { Bending moment at the bottom section } \\
\text { of the main tower }(\mathrm{MN} \cdot \mathrm{m})\end{array}$ & 275.0 & 509.4 & 275.0 & 275.0 \\
\hline \multirow{3}{*}{$\begin{array}{l}\text { Seismic } \\
\text { excitations }\end{array}$} & $\begin{array}{c}\text { Displacement at the end section of the } \\
\text { main girder }(\mathrm{m})\end{array}$ & 1.033 & 0.634 & 0.473 & 0.202 \\
\hline & $\begin{array}{l}\text { Relative displacement of the main } \\
\text { girder between the main bridge and the } \\
\text { approach bridge }(\mathrm{m})\end{array}$ & 0.635 & 0.230 & 0.153 & 0.157 \\
\hline & $\begin{array}{l}\text { Bending moment at the bottom section } \\
\text { of the main tower }(\mathrm{MN} \cdot \mathrm{m})\end{array}$ & 6070.3 & 7409.5 & 4379.1 & 6940.5 \\
\hline
\end{tabular}

Temperature action includes a system temperature difference of $30^{\circ} \mathrm{C}$, a bridge deck positive temperature difference of $14^{\circ} \mathrm{C}$, a bridge deck negative temperature difference of $-7^{\circ} \mathrm{C}$, and a tower body temperature difference of $5^{\circ} \mathrm{C}$.

$58.5 \%$, respectively. The viscous damper system has the minimum relative displacement of the main girder between the main bridge and the approach bridge, which can effectively avoid the harmful collisions that may occur at the expansion joint device under seismic excitations, and it has the smallest bending moment at the bottom section of the main tower, which can significantly reduce the scale of the main tower's foundation.

The unconstrained system has the largest displacement response and should not be used. Compared with the unconstrained system, the displacement reduction of the elastic cable system is not obvious, but the seismic excitations are concentrated on the main tower, which causes its bending moment to show a greater increase. The speed lock-up device system can significantly reduce the displacement at the end section of the main girder, but the bending moment at the bottom section of the main tower increases greatly, and both systems require a large main tower foundation and are not suitable for adoption. The viscous damper system can significantly reduce the bending moment at the bottom section of the main tower, the relative displacement of the main girder between the main bridge and the approach bridge is the smallest, the hysteretic energy consumption is good, and the damping effect is remarkable, which is a rational longitudinal seismic energy dissipation system. The bridge uses a viscous damper system.

\subsection{Comparison and Selection of Viscous Damper Setting} Position. Four viscous damper setting schemes were designed to investigate the influence of the viscous damper setting position on the structure's critical response under seismic excitations. In scheme 1 , four viscous dampers are arranged under each main tower. In scheme 2, four viscous dampers are arranged under each main tower and two for each auxiliary pier. In scheme 3 , four viscous dampers are arranged under each main tower and two for each transitional pier. In scheme 4 , four viscous dampers are arranged under each main tower, two for each auxiliary pier and two for each transitional pier. Each damper's damping coefficient is $\mathrm{c}=3500 \mathrm{kN} \cdot(\mathrm{m} / \mathrm{s})^{-\alpha}$, and the velocity exponent is $\alpha=0.4$. Table 6 shows the longitudinal structural response of the four schemes' viscous damper setting positions under seismic excitations.

Several observations can be made from Table 6. Compared with scheme 1 , the displacement of the top section of the main tower and the end section of the main girder in schemes 2 and 3 is reduced by an average of $15.3 \%$ and that in scheme 4 is reduced by $25.1 \%$. The relative displacement of the main girder between the main bridge and the approach bridge is significantly reduced in scheme 2 through scheme 4 , reaching $65.5 \%, 50.0 \%$, and $66.3 \%$, respectively. On the basis of the viscous damper setting at the main tower, the addition of the viscous damper setting at the auxiliary pier or the transitional pier can effectively reduce the displacement of the structure's critical section.

Compared with scheme 1 , the bending moments at the bottom section of the main tower in scheme 2 through scheme 4 are reduced by $2.8 \% \sim 4.9 \%$, the bending moment of the auxiliary pier in schemes 2 and 4 is reduced by $23.1 \%$ and $22.6 \%$, respectively, and the bending moments of the transitional piers of schemes 3 and 4 are increased by $15.1 \%$ and $15.9 \%$, respectively. On the basis of the viscous damper setting at the main tower, the addition of the viscous damper setting at the auxiliary pier can reduce the critical section's internal force, whilst the addition of the viscous damper setting at the transitional pier is unfavourable to the foundation of the auxiliary pier and the transitional pier.

In schemes 2 to 4 , the damping forces of the viscous damper at the main tower, the auxiliary pier, and the transitional pier are almost equivalent, the viscous damper settings at the auxiliary pier and the transitional pier do not reduce the tonnage of the main tower's viscous damper, and the tonnage of damping force for each damper is large.

Viscous dampers are expensive and difficult to maintain, and its setting must consider the cost-effectiveness ratio. In 
TABLE 6: Longitudinal structural response of the four schemes viscous damper setting positions.

\begin{tabular}{|c|c|c|c|c|}
\hline Viscous damper setting position & Scheme 1 & Scheme 2 & Scheme 3 & Scheme 4 \\
\hline $\begin{array}{l}\text { Displacement of the top section of the main } \\
\text { tower }(\mathrm{m})\end{array}$ & 0.617 & 0.531 & 0.513 & 0.460 \\
\hline $\begin{array}{l}\text { Displacement of the end section of the main } \\
\text { girder }(\mathrm{m})\end{array}$ & 0.473 & 0.399 & 0.403 & 0.355 \\
\hline $\begin{array}{l}\text { Relative displacement of the main girder between the } \\
\text { main bridge and the approach bridge }(\mathrm{m})\end{array}$ & 0.153 & 0.053 & 0.077 & 0.052 \\
\hline $\begin{array}{l}\text { Bending moment at the bottom section of the main } \\
\text { tower }(\mathrm{MN} \cdot \mathrm{m})\end{array}$ & 4379.1 & 4254.7 & 4222.9 & 4165.1 \\
\hline $\begin{array}{l}\text { Bending moment at the bottom section of the } \\
\text { auxiliary pier }(\mathrm{MN} \cdot \mathrm{m})\end{array}$ & 664.9 & 511.0 & 668.9 & 514.8 \\
\hline $\begin{array}{l}\text { Bending moment at the bottom section of the } \\
\text { transitional pier }(\mathrm{MN} \cdot \mathrm{m})\end{array}$ & 586.2 & 589.3 & 677.3 & 679.2 \\
\hline Damping force of the damper at the main tower $(\mathrm{kN})$ & 3433.4 & 3385.7 & 3391.5 & 3375.6 \\
\hline $\begin{array}{l}\text { Damping force of the damper at the auxiliary } \\
\text { pier }(\mathrm{kN})\end{array}$ & - & 3329.0 & - & 3304.8 \\
\hline $\begin{array}{l}\text { Damping force of the damper at the transitional } \\
\text { pier }(\mathrm{kN})\end{array}$ & - & - & 3116.9 & 3000.8 \\
\hline
\end{tabular}

schemes 1 to 4 , the damping cost-effectiveness ratio of the unit number damper is $0.67: 0.82: 0.82: 1.00$ in turn; scheme 1 has the lowest cost-effectiveness ratio and the highest damping efficiency, followed by scheme 2 , and scheme 4 has the worst damping efficiency.

The addition of a viscous damper to the auxiliary pier and the transitional pier can reduce the critical section displacement, but it is unfavourable to some critical internal forces in the auxiliary pier and the transitional pier foundation and increases the difficulty and cost of maintenance. As far as the bridge is concerned, the damping effect of scheme 1 has already met the design requirements, and in consideration of the full life-cycle cost and cost-effectiveness ratio, the bridge adopts scheme 1 , in which viscous dampers are positioned only at the main tower.

\section{Parameter Optimisation of Viscous Damper}

5.1. Selection of Viscous Damper Parameters. To reasonably determine the value of the viscous damper parameters, for the seismic excitations with an exceedance probability of $4 \%$ in 100 years, under different combinations of viscous damper parameters, an explicit time-domain dimension-reduced iteration method is carried out for nonlinear time-history analysis of the bridge. The law between the viscous damper parameters and the structure's seismic response are studied. Four viscous dampers are installed between the lower crossbeam of the main tower and the bottom plate of the main girder for each main tower, and a total of eight viscous dampers are installed in the whole bridge, as illustrated in Figure 11. Under the same working conditions, a uniform damper damping coefficient cand velocity exponent $\alpha$ are taken. The damping coefficient $c$ of the viscous damper ranges from 1000 to $6000 \mathrm{kN} \cdot(\mathrm{m} / \mathrm{s})^{-\alpha}$ in increments of $500 \mathrm{kN} \cdot(\mathrm{m} / \mathrm{s})^{-\alpha}$. The velocity exponent $\alpha$ varies from 0.2 to 0.7 in increments of 0.1 . The number of analytical conditions is 66 .

The relationship between the viscous damper parameters and the longitudinal displacement of the end section of the main girder under seismic excitation is shown in Figure 12.
The relationship between the viscous damper parameters and the longitudinal displacement of the top section of the main tower is shown in Figure 13. The relationship between the viscous damper parameters and the longitudinal bending moment at the bottom section of the main tower is shown in Figure 14. The relationship between the viscous damper parameters and the viscous damper seismic stroke is shown in Figure 15.

Several observations can be made from Figures 12 and 13. Under the same damping coefficient $c$, the longitudinal top section of the main tower and the end section of the main girder increase slowly as the velocity exponent $\alpha$ increases. Under the same velocity exponent $\alpha$, the longitudinal top section of the main tower and the end section of the main girder decrease as the damping coefficient $c$ increases; the effect changes greatly, the attenuation is fast, and the longitudinal displacement is sensitive to the damping coefficient $c$. When the damping coefficient $c$ is greater than $5000 \mathrm{kN} \cdot(\mathrm{m} / \mathrm{s})^{-\alpha}$, the magnitude of the longitudinal displacement of the girder end and the main tower top decreases with a limited increase in the damping coefficient.

Several other observations can be made from Figure 14. When the damping coefficient $c$ is less than $5000 \mathrm{kN} \cdot(\mathrm{m} / \mathrm{s})^{-\alpha}$, the longitudinal bending moment at the bottom section of the main tower increases slowly as the velocity exponent $\alpha$ increases. However, when the damping coefficient $c$ is $5000 \mathrm{kN} \cdot(\mathrm{m} / \mathrm{s})^{-\alpha}$ or greater, the longitudinal bending moment at the bottom section of the main tower decreases slowly as the velocity exponent $\alpha$ increases and then increases slowly. When the velocity exponent $\alpha$ is less than 0.35 , the longitudinal bending moment at the bottom section of the main tower decreases as the damping coefficient $c$ increases and then increases slowly; however, when the velocity exponent $\alpha$ is 0.35 or greater, the longitudinal bending moment at the bottom section of the main tower decreases as the damping coefficient increases. When the damping coefficient $c$ is between $1000 \mathrm{kN} \cdot(\mathrm{m} / \mathrm{s})^{-\alpha}$ and $3500 \mathrm{kN} \cdot(\mathrm{m} / \mathrm{s})^{-\alpha}$, the bending moment effect decays more rapidly. 


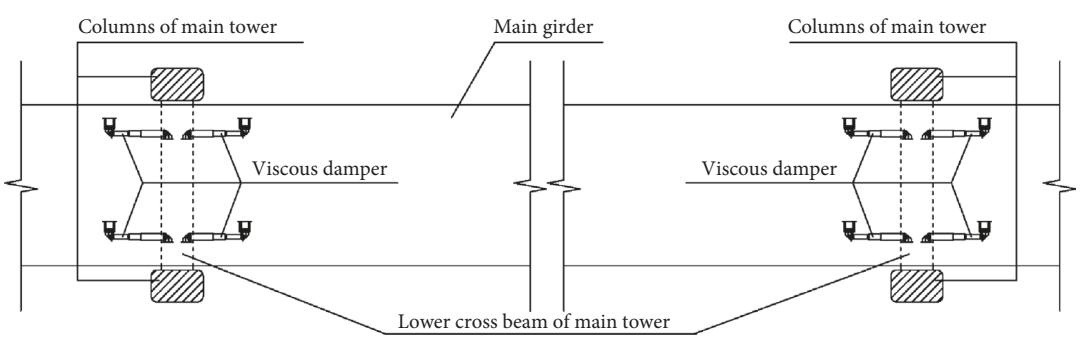

(a)

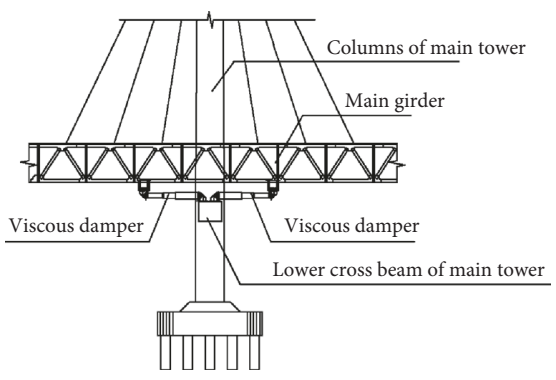

(b)

Figure 11: Locations of viscous dampers between the main tower and main girder. (a) Planar graph. (b) Elevation graph.

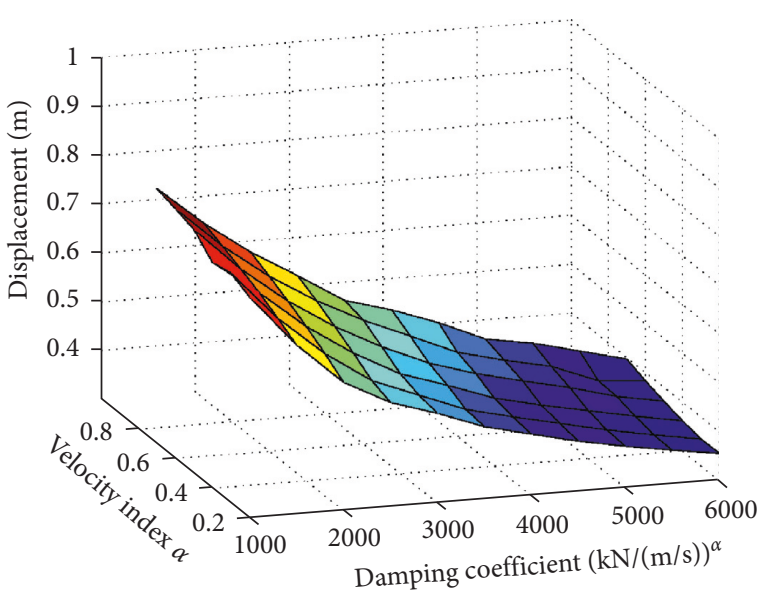

Figure 12: Longitudinal displacement of the end section of the main girder.

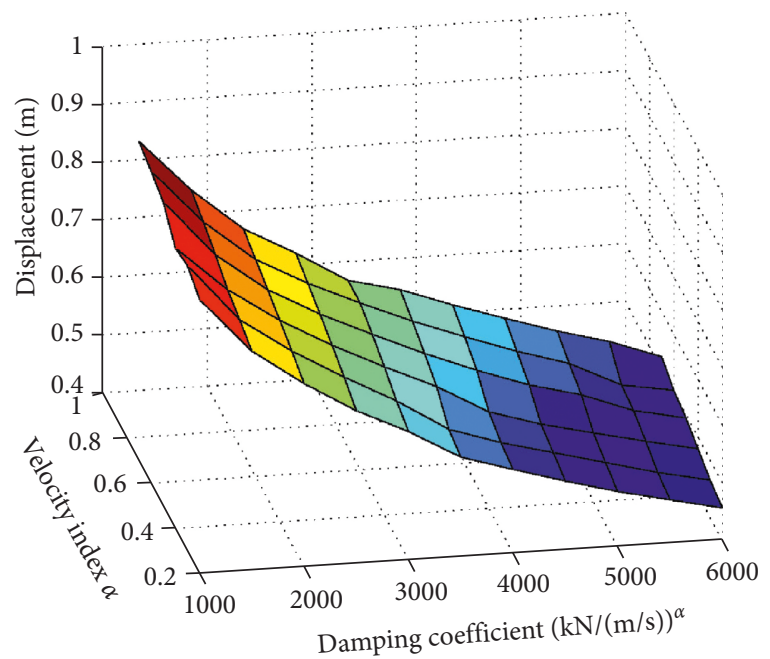

FIGURE 13: Longitudinal displacement of the top section of the main tower.

Figure 15 shows that the viscous damper stroke decreases as the damping coefficient $c$ increases and increases slowly as the velocity exponent $\alpha$ increases. When the damping coefficient $c$ is greater than 5000 , the damper stroke reduction slows.

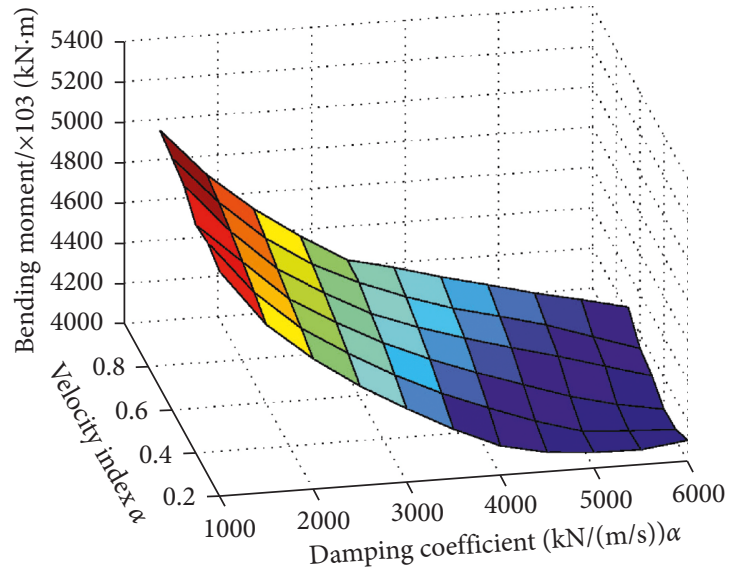

FIgURE 14: Longitudinal bending moment at the bottom section of the main tower.

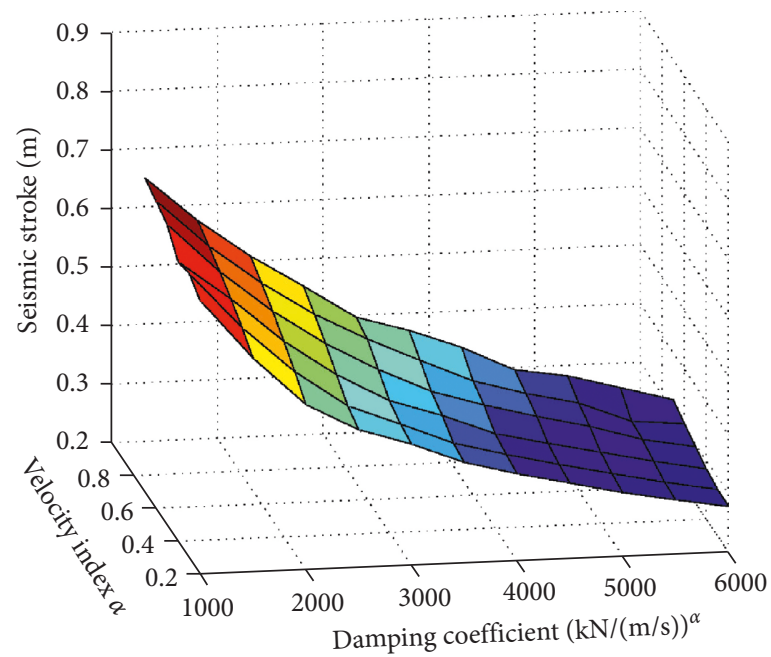

Figure 15: Viscous damper seismic stroke.

To reasonably control the basic scale of the main tower and reduce the size of the expansion joint and the viscous damper, the seismic isolation design prioritises the proper control of the structure's internal force response and secondly controls the structure's critical displacement response as much as possible and must also consider the full life-cycle 
cost of the viscous damper. Comprehensive consideration of Section 4.3 and this section shows that the reasonable ranges for the bridge's viscous damper parameters are a damping coefficient $c=3500 \sim 5000 \mathrm{kN} \cdot(\mathrm{m} / \mathrm{s})^{-\alpha}$ and a velocity exponent $\alpha=0.35 \sim 0.5$.

\subsection{Influence of Straddle-type Monorail Traffic Braking on the} Selection of Viscous Damper Parameters. With reference to the normal railway train braking-force loading time course [13], the braking force-loading time-history curve of the straddle-type monorail train at an initial speed of $80 \mathrm{~km} / \mathrm{h}$ is shown in Figure 16, where $w$ is the train's self-weight; the train deceleration varies from 0.0 to $0.1 \mathrm{~g}$ for a duration of $6 \mathrm{~s}$; the maximum deceleration time is $18.81 \mathrm{~s}$ and the braking deceleration peak value is $0.20 \mathrm{~g}$. Considering a combination of four damper parameters, the damping coefficient is $c=1000 \mathrm{kN} \cdot(\mathrm{m} / \mathrm{s})^{-\alpha}$ or $c=6000 \mathrm{kN} \cdot(\mathrm{m} / \mathrm{s})^{-\alpha}$ and the velocity exponent is $\alpha=0.2$ or $\alpha=0.7$. The two-line straddle-monorail train has the same direction and the same position braking action and stops in the main span, which is the most unfavourable situation for the bridge.

The longitudinal deformation of the movable support at the main tower is shown in Figure 17. And, the frictional force of the movable support at the main tower is shown in Figure 18, and the longitudinal bending moment at the bottom section of the main tower is shown in Figure 19.

Several observations can be made from Figures 17 to 19. During the straddle-type monorail train's braking process, the deformation of the movable support at the main tower gradually increases. The bridge is freely attenuated after the train brake stops on the bridge. The peak friction of the movable support at the main tower decreases slowly as the damping coefficient $c$ increases and increases as the velocity exponent $\alpha$ increases. In the four-damper parameter combination, the peak value of the friction of the movable support is $102.1 \mathrm{kN}$, as shown in Figure 18, which is smaller than the yielding force $F_{y}=120 \mathrm{kN}$ in Table 2, and there is no relative sliding of the movable support. The deformation of the movable support is the internal deformation of the structural material. Relative sliding of the support does not occur, which can also be explained from the static analysis. The straddle-type monorail traffic adopts a two-line design; the train load design axle weight is $140 \mathrm{kN}$ and is grouped by six vehicles, with a total weight of $6720 \mathrm{kN}$. When the peak value of the deceleration of the twin-line train is $0.20 \mathrm{~g}$, the corresponding maximum total braking force is $1344 \mathrm{kN}$, which is less than the yielding force of $2754 \mathrm{kN}$ provided by all supports of the main bridge in Table 3, and relative slipping of the movable support will not occur.

The peak value of the longitudinal bending moment of the bottom section of the main tower slowly increases as the damping coefficient $c$ increases and decreases as the velocity exponent $\alpha$ increases. The maximum value of the longitudinal bending moment of the bottom section of the main tower is $22,410 \mathrm{kN} \cdot \mathrm{m}$, as shown in Figure 19, which is much smaller than the peak of the seismic excitations. The straddle-type monorail traffic braking effect does not control the structural design.

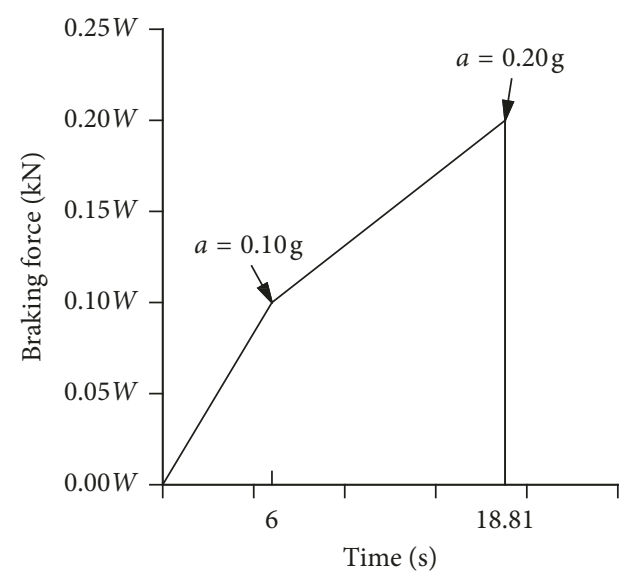

FIGURE 16: Braking force-loading time-history curve.

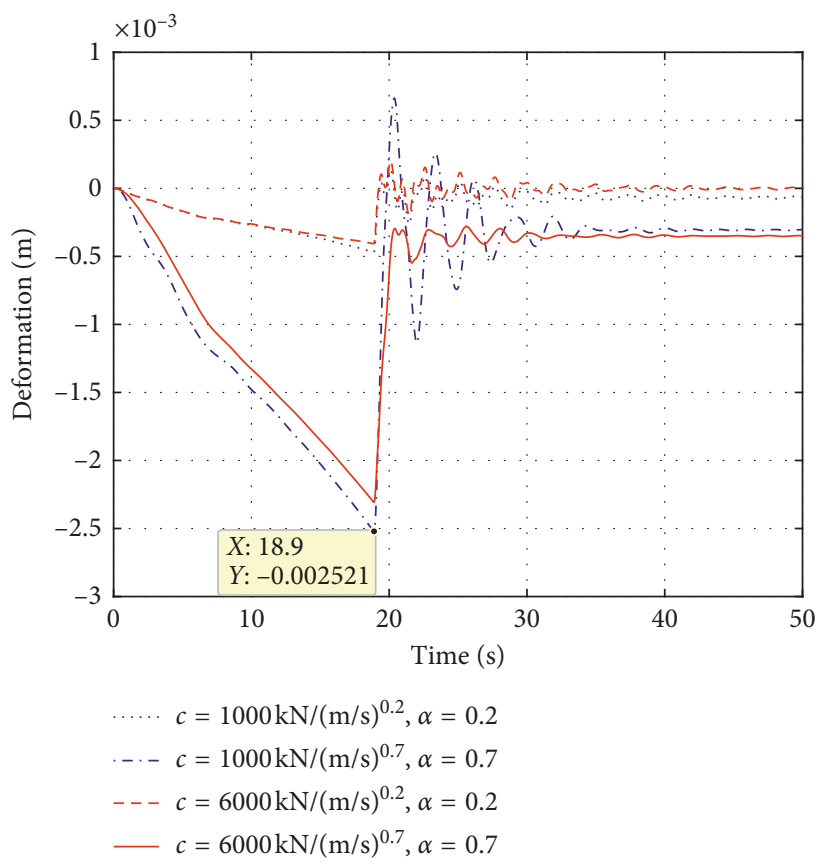

Figure 17: Longitudinal deformation of the movable support.

Due to the small total mass of the straddle monorail and the low initial braking velocity, the static friction of the straddle-type monorail-cum-road long-span cable-stayed bridge support can resist the train's braking force. During the train's braking process, no viscous damper is required to participate in the work, and the parameters of the viscous damper can be selected regardless of the train braking.

5.3. Influence of Straddle-type Monorail Traffic Running on the Selection of Viscous Damper Parameters. Regardless of running comfort and other issues, the moving load is used to simulate the running process of the straddle-type monorail traffic, and the relationship between the bridge's longitudinal response and the viscous damper parameters is studied. Consider a four-damper parameter combination; the damping coefficient is $c=1000 \mathrm{kN} \cdot(\mathrm{m} / \mathrm{s})^{-\alpha}$ or 


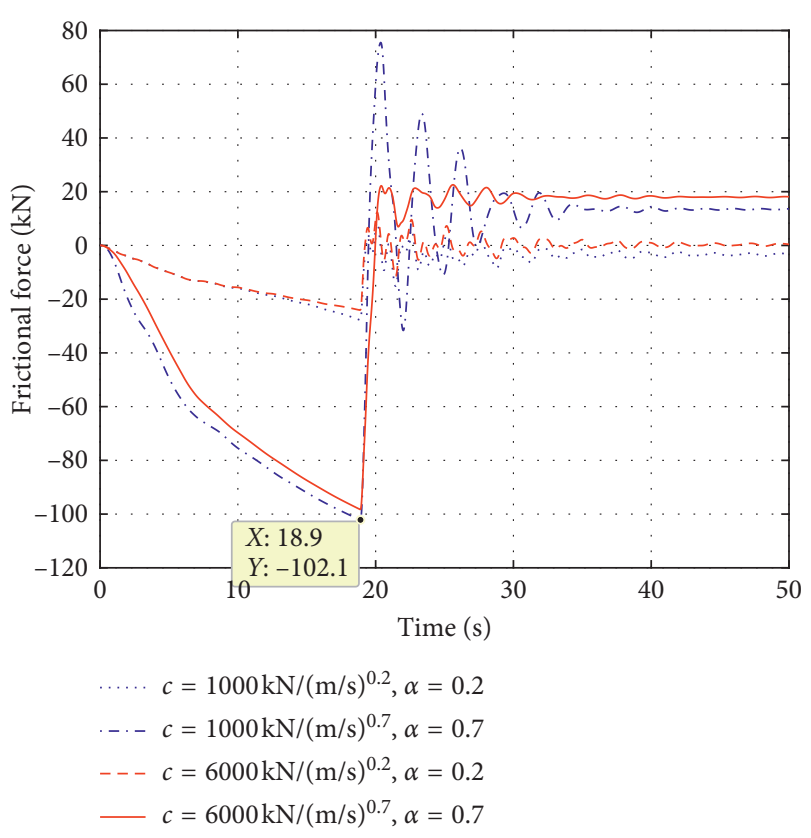

FIgURE 18: Frictional force of the movable support.

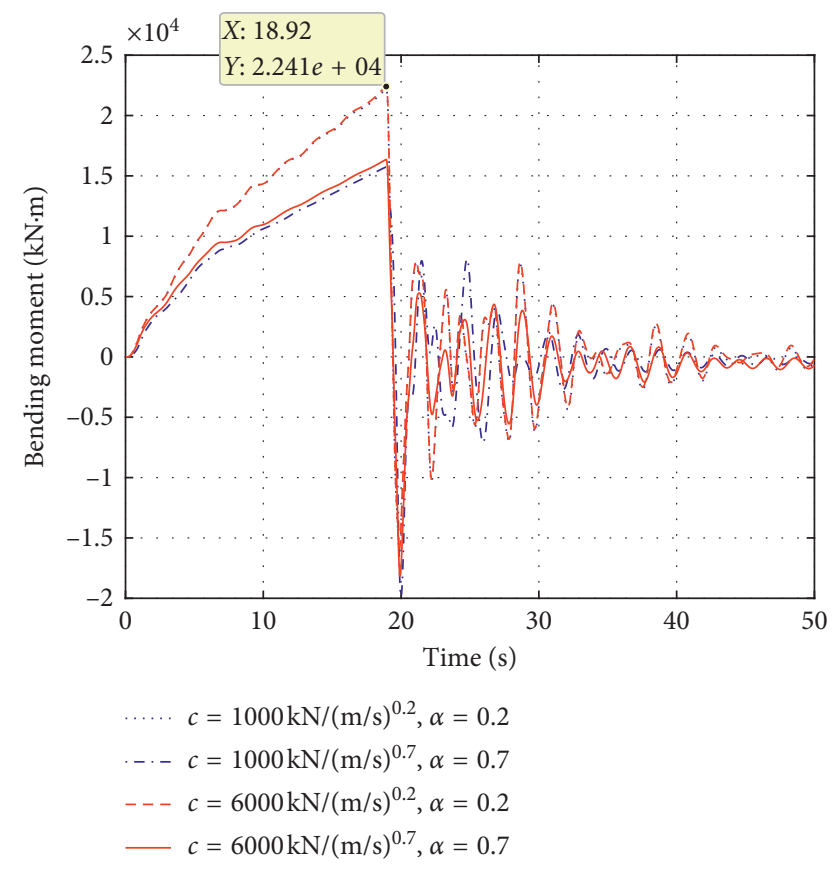

FIGURE 19: Longitudinal bending moment at the bottom section of the main tower.

$c=6000 \mathrm{kN} \cdot(\mathrm{m} / \mathrm{s})^{-\alpha}$ and the velocity exponent is $\alpha=0.2$ or $\alpha=0.7$. The train consists of one first vehicle + four standard vehicles + one first vehicle, the standard vehicle length is $14.8 \mathrm{~m}$ and the first vehicle length is $15.5 \mathrm{~m}$. In the analysis, each vehicle's axle load is represented by four concentrated forces $(4 \times 140 \mathrm{kN})$. The vehicle's axle load is simplified into a series of moving concentrated forces; the action position is the actual action point of each wheel, and the concentration force is equal to the wheel axle load. The straddle-type monorail traffic running speed is $v=80 \mathrm{~km} / \mathrm{h}$. The simplified loading model of a straddle-type monorail traffic running cable-stayed bridge is shown in Figure 20. Each concentrated force is numbered as $p_{i}$ according to the direction in which the train travels. Assuming that the two-line straddle-monorail traffic has the same direction and the same speed running across the cable-stayed bridge, the first concentrated force enters the bridge at the initial zero time, the time of the $i$-th load entering the bridge can be expressed as $t_{i}=l_{i} / v$.

The longitudinal displacement of the end section of the main girder is shown in Figure 21, and the viscous damper damping force is shown in Figure 22.

It can be seen from Figures 21 and 22 that the maximum damper peak value is $3.8 \mathrm{~mm}$ and the maximum damping force peak value is $361.7 \mathrm{kN}$. The peak value of the structural response is small while the train is running, much smaller than the peak value of seismic excitations, and the structural design is not controlled by the running process of the straddle-type monorail traffic. The viscous damper is not required to suppress the structure's longitudinal vibration while the straddle-type monorail traffic is running.

The viscous damper is set for an earthquake with a low probability of occurrence. During the train's daily running, the longitudinal velocity of the main girder is much lower than that during a strong earthquake. The seismic viscous damper is also working, which makes the viscous damper easy to wear; the viscous damper design is not required to account for the low-speed conditions of the train's daily running. Because the longitudinal vibration velocity of the main girder is low $(1.4 \mathrm{~mm} / \mathrm{s})$, while the train is running, and the damping force decreases rapidly as the velocity exponent $\alpha$ increases, the damping force is sensitive to the velocity exponent $\alpha$. Therefore, the velocity exponent $\alpha$ can take a suitably large value to increase the viscous damper's working velocity to reduce the damper's participation in the process of the train crossing the bridge, thereby improving the durability of the viscous damper. However, when the velocity exponent $\alpha$ is large, the seismic efficiency of the viscous damper will be affected. After comprehensive consideration of the earthquake's action, the trains' running action, and the life-time cost of viscous dampers, the bridge viscous damper is designed with a damping coefficient $c=4000 \mathrm{kN} \cdot(\mathrm{m} / \mathrm{s})^{-\alpha}$ and a velocity exponent $\alpha=0.4$.

\section{Conclusions}

A longitudinal seismic energy dissipation system for straddle-type monorail-cum-road long-span cable-stayed bridge has been selected and optimised in this study.

(1) Compared with the unconstrained system, the elastic cable system, and the speed lock-up device, the viscous damper system can significantly reduce the bending moment at the bottom section of the main tower. The relative displacement of the main girder between the main bridge and the approach bridge is the lowest, the hysteretic energy consumption is good, and the damping effect is remarkable; thus, it is 


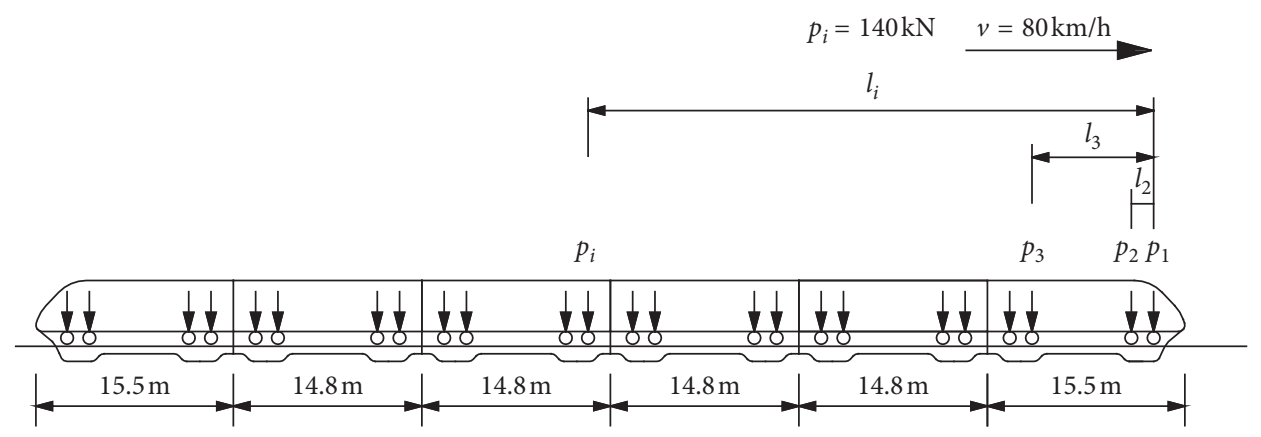

FIGURE 20: Simplified loading model of a straddle-type monorail traffic running cable-stayed bridge.

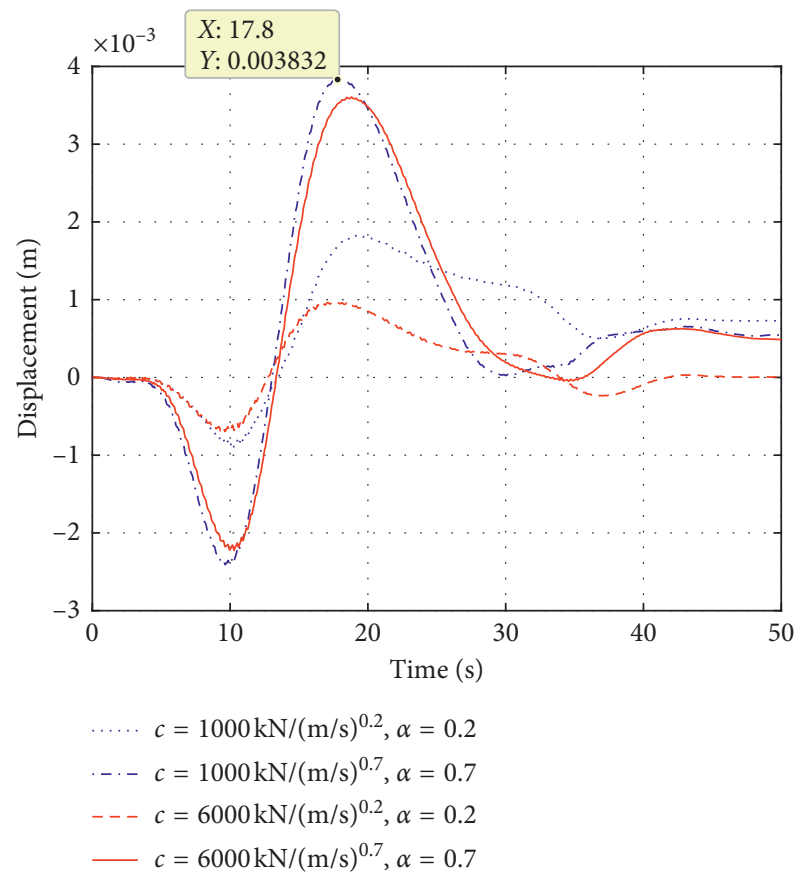

FIgURE 21: Longitudinal displacement of the end section of the main girder.

an ideal longitudinal seismic energy dissipation system for straddle-type monorail-cum-road longspan cable-stayed bridges.

(2) The damping efficiency of the unit number damper is the highest with the viscous damper installed only at the main tower, and the damper effect is the best when the viscous damper is installed both at the main tower and at the auxiliary pier, but the transitional pier is unfavourable when the viscous damper is installed at the transitional pier.

(3) In general, the critical response of a straddle-type monorail-cum-road long-span cable-stayed bridge decreases as the damping coefficient increases and increases slowly as the velocity exponent increases, but the longitudinal bending moment at the bottom section of the main tower does not change monotonically with the damper parameters.

(4) Due to the small total mass of the straddle monorail and the low initial braking velocity, the static friction

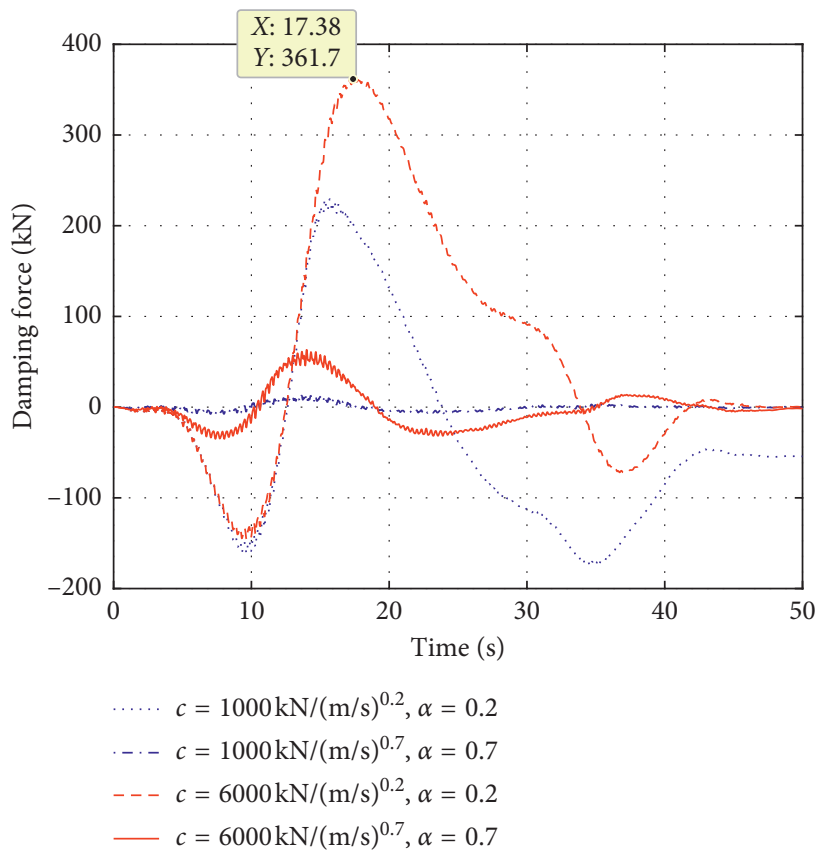

FIGURE 22: Viscous damper damping force.

of the straddle-type monorail-cum-road long-span cable-stayed bridge support can resist the train's braking force, and the parameters of the viscous damper can be selected regardless of train braking.

(5) While straddle-type monorail traffic is running, the viscous damper is not required to suppress the structure's longitudinal vibration, and it can take a suitably large value of velocity exponent $\alpha$ to increase the working velocity of the viscous damper to reduce the damper's participation in the process of the train crossing the bridge, thereby improving the durability of the viscous damper.

\section{Data Availability}

The data used to support the findings of this study are available from the corresponding author upon request.

\section{Conflicts of Interest}

The authors declare that they have no conflicts of interest. 


\section{Acknowledgments}

This work was supported by the National Natural Science Foundation of China (51678252) and the Science and Technology Program of Guangzhou, China (201804020069).

\section{References}

[1] Z. Y. Gao, "Technical characteristics of main bridge of Hutong Changjiang river bridge," Bridge Construction, vol. 44, no. 2, pp. 1-5, 2014, in Chinese.

[2] H. S. Ruan, A. P. Qu, Y. D. He, and L. A. Li, "Study of structural seismic response characteristics of long span railcum-road steel truss girder cable-stayed bridges," Bridge Construction, vol. 45, no. 2, pp. 32-38, 2015, in Chinese.

[3] H. S. Ruan, L. A. Li, G. W. Yang, and Y. D. He, "Study of seismic techniques for Huanggang Changjiang river rail-cumroad bridge," Bridge Construction, vol. 43, no. 6, pp. 34-39, 2013, in Chinese.

[4] F. F. Geng and Y. L. Ding, "Multiobjective optimal control of longitudinal seismic response of a multitower cable-stayed bridge," Shock and Vibration, vol. 2016, Article ID 6217587, p. 13, 2016.

[5] C. He, S. Z. Qiang, and M. Liu, "Analysis of different longitudinal restraint conditions in main girder and their effects on the seismic behaviour of Wuhan white shoal Yangtz river bridge," China Journal of Highway and Transport, vol. 12, no. 4, pp. 22-28, 1999, in Chinese.

[6] D. Wang and P. M. Huang, "Research on deck-tower connection of super long-span cable-stayed bridge," Journal of Zhengzhou University (Engineering Science), vol. 29, no. 4, pp. 112-115, 2008, in Chinese.

[7] Z. G. Guan, H. You, and J. Z. Li, "Lateral isolation system of a long-span cable-stayed bridge with heavyweight concrete girder in a high seismic region," Journal of Bridge Engineering, vol. 22, no. 1, Article ID 04016104, 2017.

[8] B. B. Soneji and R. S. Jangid, "Passive hybrid systems for earthquake protection of cable-stayed bridge," Engineering Structures, vol. 29, no. 1, pp. 57-70, 2007.

[9] A. J. Ye, S. D. Hu, and L. C. Fan, "Seismic displacement control for super-long-span cable-stayed bridges," China Civil Engineering Journal, vol. 37, no. 12, pp. 38-43, 2004, in Chinese.

[10] S. P. Wu, C. Zhang, and Z. Z. Fang, "Design schemes and parameter regression analysis of viscous dampers for cablestayed bridge," Bridge Construction, vol. 44, no. 5, pp. 21-26, 2014, in Chinese.

[11] C. Y. Jiao, J. Z. Li, and T. B. Peng, "Effects of different connecting styles between towers and deck on seismic responses of a long-span cable-stayed bridge," Journal of Vibration and Shock, vol. 28, no. 10, pp. 179-234, 2009, in Chinese.

[12] H. Guo, Y. Q. Li, S. T. Hu, and X. L. Ban, "Research on earthquake response of highway and railway shared cablestayed bridge with $532 \mathrm{~m}$-main span and vibration-reducing effect of damper," Railway Engineering, vol. 1, pp. 14-18, 2015, in Chinese.

[13] L. Lyu and J. Z. Li, "Study on vibration control effect of viscous dampers for rail-cum-road cable-stayed bridge during earthquake, train braking and running," Engineering $\mathrm{Me}$ chanics, vol. 32, no. 12, pp. 139-146, 2015, in Chinese.

[14] S. Q. Qin and W. L. Qu, "Hybrid control of longitudinal vibration responses in deck of Tianxingzhou rail-cum-road cable-stayed bridge caused by earthquake, train braking and vehicle moving loads," Bridge Construction, vol. 4, pp. 1-9, 2008, in Chinese.

[15] X. W. Wang, B. Zhu, and S. G. Cui, "Research on collapse process of cable-stayed bridges under strong seismic excitations," Shock and Vibration, vol. 2017, Article ID 7185281, 18 pages, 2017.

[16] J. Guo, J. Zhong, X. Dang, and W. Yuan, "Seismic responses of a cable-stayed bridge with consideration of uniform temperature load," Applied Sciences, vol. 6, no. 12, p. 408, 2016.

[17] C.-W. Kim, M. Kawatani, C.-H. Lee, and N. Nishimura, "Seismic response of a monorail bridge incorporating trainbridge interaction," Structural Engineering and Mechanics, vol. 26, no. 2, pp. 111-126, 2007.

[18] C.-W. Kim and M. Kawatani, "Effect of train dynamics on seismic response of steel monorail bridges under moderate ground motion," Earthquake Engineering \& Structural Dynamics, vol. 35, no. 10, pp. 1225-1245, 2006.

[19] C. H. Lee, M. Kawatani, C. W. Kim, N. Nishimura, and Y. Kobayashi, "Dynamic response of a monorail steel bridge under a moving train," Journal of Sound and Vibration, vol. 294, no. 3, pp. 562-579, 2006.

[20] H. Wang, E. Zhu, and Z. Chen, "Dynamic response analysis of the straddle-type monorail bridge-vehicle coupling system," Urban Rail Transit, vol. 3, no. 3, pp. 172-181, 2017.

[21] R. Wei and J. Li, "Summary of research on vehicle-bridge vibration of straddle-type monorail transportation," Auto Industry Research, vol. 9, pp. 44-49, 2018, in Chinese.

[22] Y. L. Li, Q. F. Qiao, K. J. Chen, Y. P. Zeng, and H. Y. Xiang, "Study of vehicle-induced longitudinal vibration and connection between pylon and girder of long span railway cablestayed bridge," Bridge Construction, vol. 44, no. 2, pp. 12-19, 2014, in Chinese.

[23] C. Su, B. M. Li, T. C. Chen, X. Liang, and X. H. Dai, "Nonlinear random vibration analysis of energy-dissipation structures with viscous dampers by random simulation method based on explicit time-domain dimension-reduced iteration scheme," Chinese Journal of Computational Mechanics, vol. 33, no. 4, pp. 556-563, 2016, in Chinese.

[24] C. Su, X. Liu, B. Li, and Z. Huang, "Inelastic response analysis of bridges subjected to non-stationary seismic excitations by efficient MCS based on explicit time-domain method," Nonlinear Dynamics, vol. 94, no. 3, pp. 2097-2114, 2018.

[25] C. Su, B. Li, T. Chen, and X. Dai, "Stochastic optimal design of nonlinear viscous dampers for large-scale structures subjected to non-stationary seismic excitations based on dimensionreduced explicit method," Engineering Structures, vol. 175, pp. 217-230, 2018. 


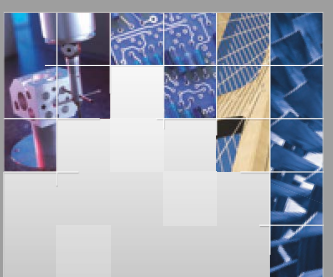

\section{Enfincering}
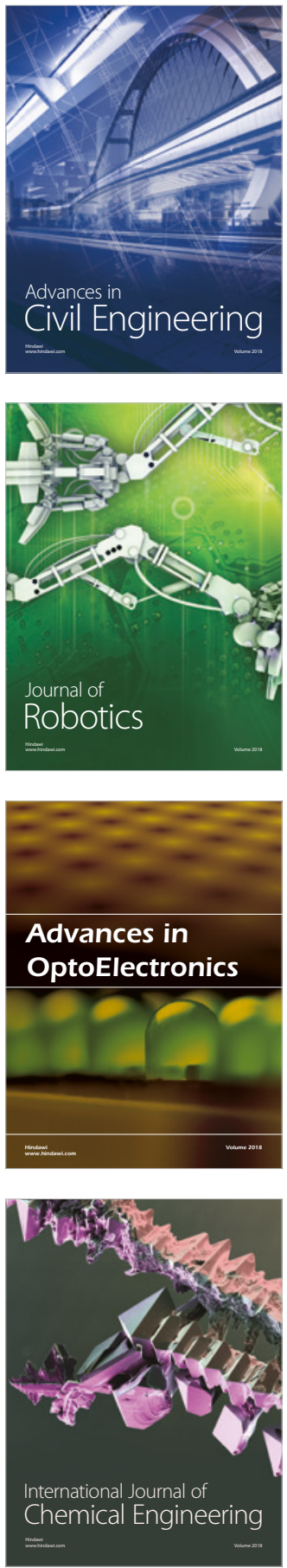

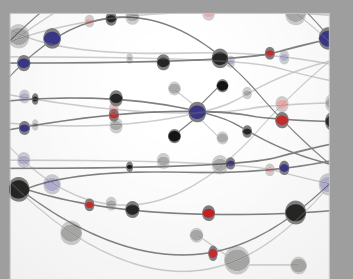

\section{Rotating \\ Machinery}

The Scientific World Journal

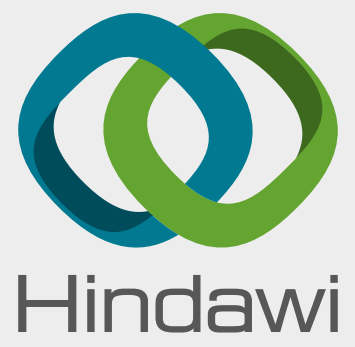

Submit your manuscripts at

www.hindawi.com
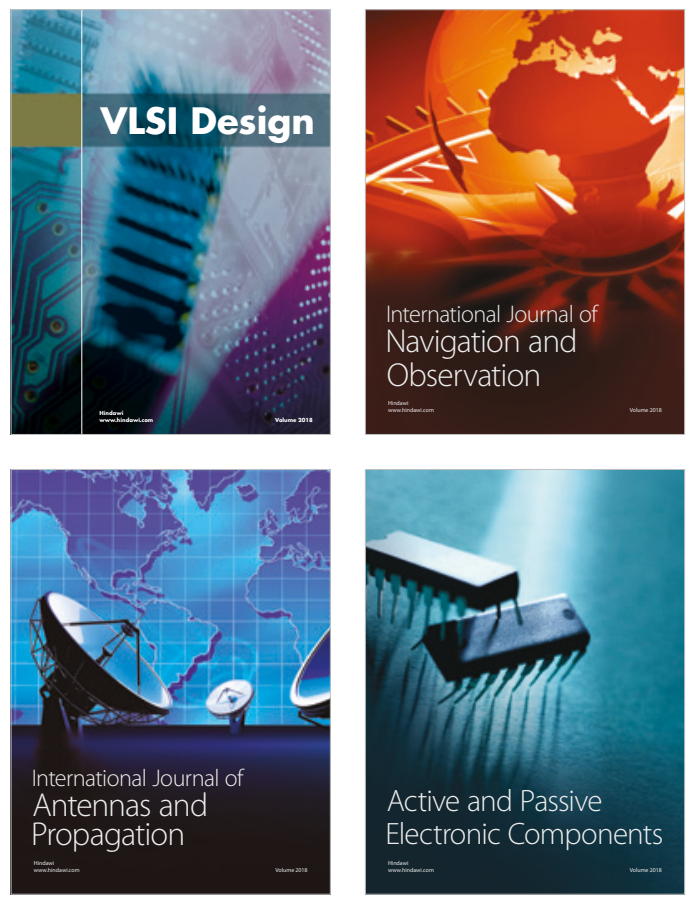
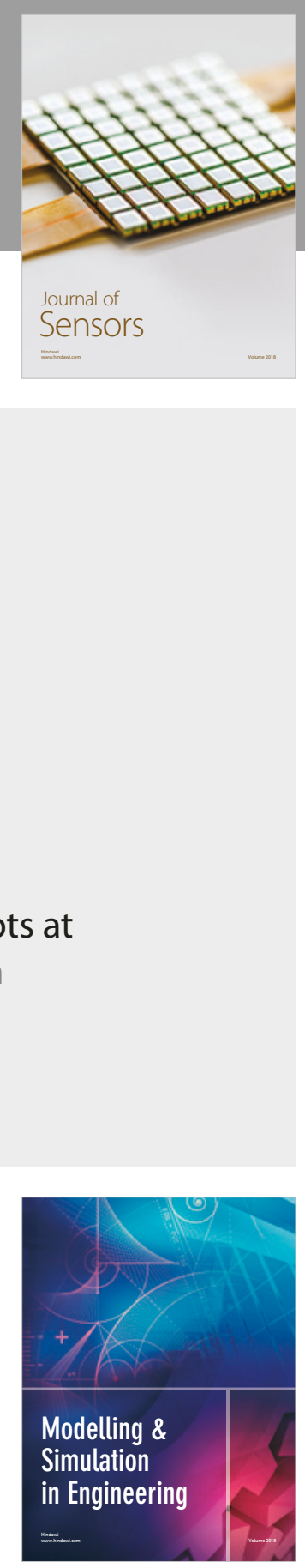

\section{Advances \\ Multimedia}
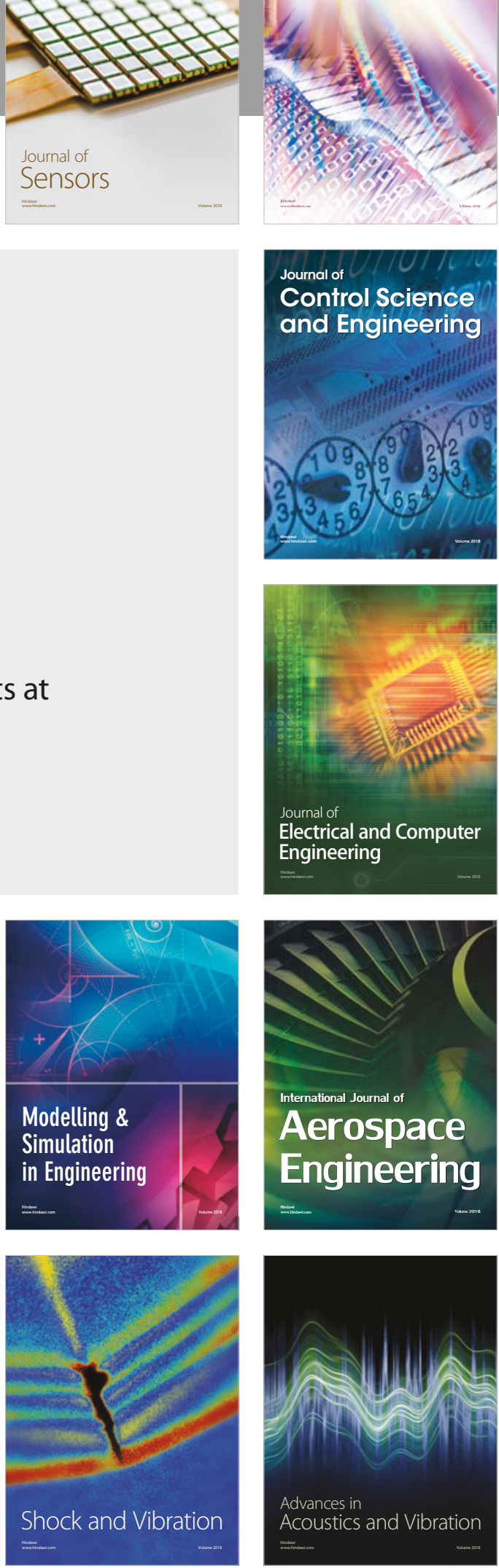